\title{
Las monedas de la villa romana del Pou de la Sargueta (Riba-roja de Túria, València)
}

\section{The Coins of the Roman Villa from Pou de la Sargueta (Riba-roja de Túria, Valencia)}

\section{David MARTínez Chico}

Universitat de València. Departament de Prehistòria, Arqueologia i Història Antiga.

Grup d'Investigació en Arqueologia del Mediterrani (GRAM)

Av. de Blasco Ibáñez, 28, E-46010 València

david_ele@live.com

\section{IGNACIO HORTELANO UCEDA \\ C/ Organista Plasencia, 40, 5. ${ }^{\text {a }}$, E-46006 València \\ ignacio.hortelano@gmail.com}

Se estudia el material numismático procedente de la villa del Pou de la Sargueta, en Riba-roja de Túria (València). La mayor parte de las monedas corresponde al siglo III dC y procede de contextos relacionados con las reformas acometidas en el establecimiento a finales de dicha centuria. La práctica supresión del suministro monetal documentada en el siglo iv dC en la villa se alivió con el numerario de imitación, fechable desde finales del siglo III dC y con una perduración en el registro arqueológico hasta finales del siglo IV dC. Precisamente de este último siglo se ha documentado una excepcional moneda perteneciente al usurpador Nepociano. Las conclusiones aportan nuevos datos sobre la monetización rural para el territorium de Valentia.

\section{PALABRAS CLAVE}

HALLAZGOS MONETARIOS, VILLA ROMANA, VALENTIA, CIRCULACIÓN MONETARIA, IMITACIONES

This paper aims to study the numismatic material exhumed from the villa of Pou de la Sargueta, in Riba-roja de Túria (Valencia). Most of the coins correspond to the $3^{\text {rd }}$ century A.D. and come from contexts related to the reforms undertaken in the establishment at the end of this same century. The almost suppression of the coin-supply caused in the $4^{\text {th }}$ century A.D. in the villa was relieved with the imitative, dateable coinage between the end of the $3^{\text {rd }}$ century A.D., and with a lasting period in the archaeological record until the end of the $4^{\text {th }}$ century A.D. Precisely, from this last century an exceptional coin of Nepotianus has been recorded. The conclusions provide new data on rural monetization in Valentia's territory.

\section{KEYWORDS}

COIN FINDS, ROMAN VILLA, VALENTIA, MONETARY CIRCULATION, IMITATIONS 


\section{La villa romana del Pou de la Sargueta}

La villa de la partida del Pou de la Sargueta fue descubierta con ocasión de una promoción pública de suelo industrial en el municipio de Riba-roja de Túria. ${ }^{1}$ Se localiza en el paraje natural del Pla de Quart, una amplia y fértil penillanura aluvial que se extiende, delimitada entre la ribera sur del río Turia, las suaves elevaciones de los Carasoles de Riba-roja, las lomas de Les Rodanes y la Serra Perenxisa, en el hinterland de la antigua Valentia. Geológicamente la comarca se caracteriza por sus ricos suelos de arcillas y limos y por la presencia de fuentes y acuíferos poco profundos fácilmente aprovechables para el riego (Carmona González y Ruiz Pérez, 2007), lo que ha favorecido un intenso poblamiento rural desde la Antigüedad.

El asentamiento dista escasos $15 \mathrm{~km}$ de la ciudad (fig. 1), con la que se comunicaba por medio de la vía que, a través del Portillo de Buñol y la Plana de Utiel, discurría hasta Segobriga (Arasa Gil y Rosselló Verger, 1995: 124-125; Palomero Plaza, 1987) y vertebraba el oeste del ager valentinus. Los rastros de las estructuras centuriadas que ordenaron este territorio, identificados inicialmente por Cano García (1974) y Pingarrón Seco (1980), fueron posteriormente revisados por González Villaescusa (1996; 2002 y 2007) quien distinguió tres catastros diferentes que, en parte, pudieron beneficiarse de las aguas del Turia por medio de extensas redes de acueductos como las del sistema Vilamarxant-Ribaroja-Manises (Hortelano Uceda, 2008).

Aunque se han identificado algunas estructuras de mampostería careada que se datan en la segunda mitad del siglo I dC, el proyecto constructivo de la villa como tal se fecha en época antonina. Con más de 1,65 ha de extensión, el establecimiento se concibió como un conjunto vallado de edificios independientes que se articularon en torno a patios configurando las distintas unidades funcionales (Hortelano Uceda, 2007 y 2011-2012). Corresponden a esta fase construcciones de opus caementicium con pavimentos de mortero de cal que definieron las partes urbana, fructuaria y rustica que formaron el entramado básico de la instalación (fig. 2).

La vivienda principal contaba con un atrio porticado que fue adornado con una fuente trilobulada. A él se abrían los cubicula, el oecus y un triclinium comunicado con habitaciones traseras de servicio. Un pequeño deambulacrum permitía el acceso desde esta zona hacia un patio privado trasero, usado como palestra ajardinada antepuesta a un balneum de $185 \mathrm{~m}^{2}$. Este disponía de apodyterium, frigidarium, tepidarium y caldarium, colocados contiguamente en disposición lineal axial. También contó con una natatio de más de $40 \mathrm{~m}^{2}$ y con unas latrinae exteriores construidas sobre su canalización de desagüe.

1. Las obras, promovidas desde la Conselleria de Infraestructuras de la Generalitat Valenciana, motivaron el desarrollo de tres campañas sucesivas de excavación arqueológica entre los años 2005 y 2007 que permitieron delimitar en planta la villa, identificar funcionalmente su organización espacial y definir su evolución cronológica. Estas excavaciones fueron dirigidas por Ignacio Hortelano Uceda. El material numismático presentado en este artículo está depositado en el Museu de Prehistòria de València, donde se ha llevado a cabo su clasificación y estudio por parte de David Martínez Chico. Agradecemos a su conservador Manuel Gozalbes Fernández de Palencia las facilidades prestadas. 
Figura 1. Localización del Pou de la Sargueta en relación con las principales ciudades de su entorno (elaboración: D. Martínez Chico).
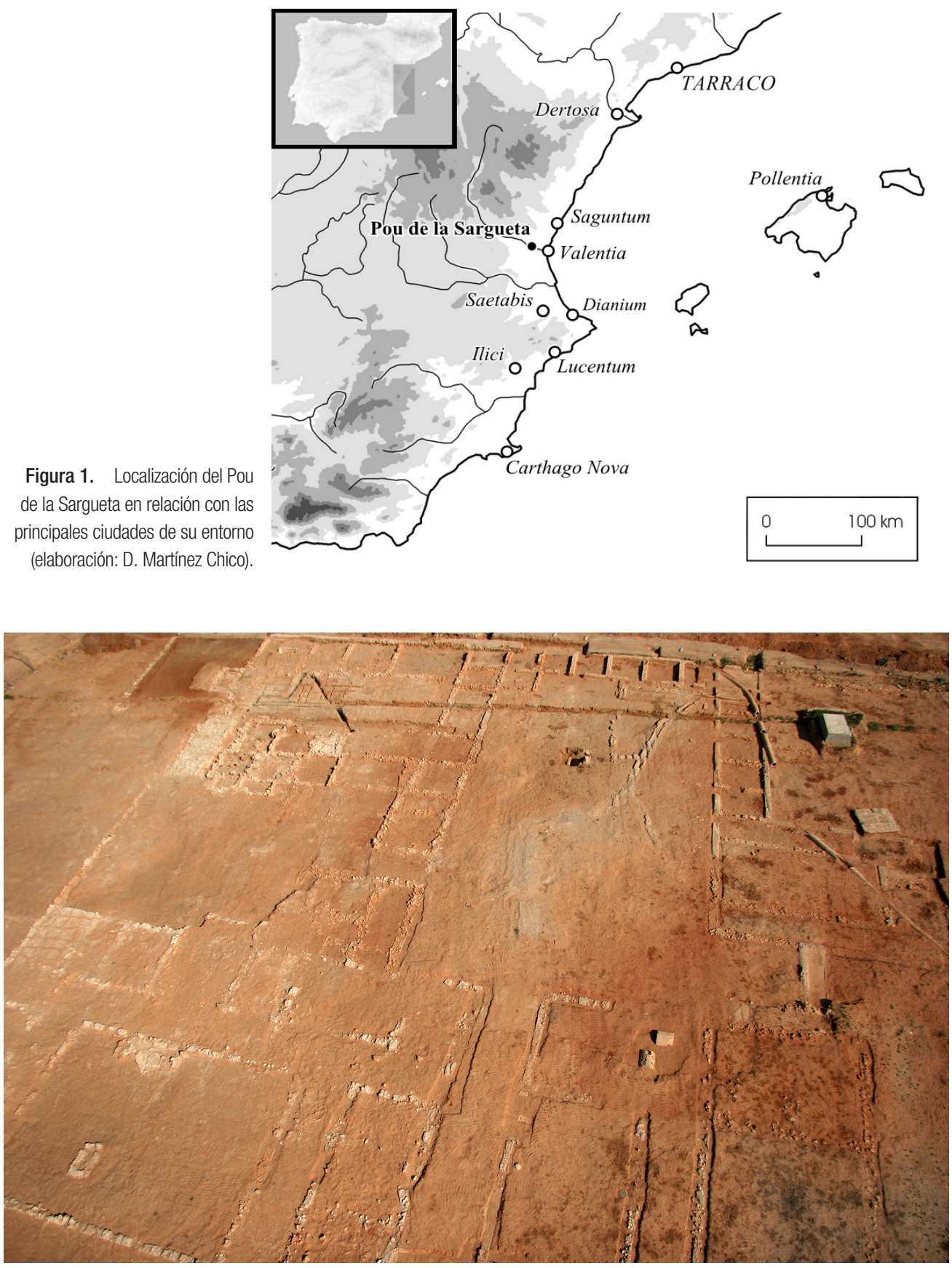

Figura 2. Vista aérea de la villa romana del Pou de la Sargueta desde el sur (imagen: I. Hortelano Uceda). 
Las instalaciones productivas se dedicaron principalmente a la manufactura del vino y del aceite, que se desarrolló sucesivamente en sendos torcularia, uno de ellos dotado de un sistema doble de prensas de tornillo con contrapesos cilíndricos de piedra local. Ambos disponían de depósitos de decantación y envasado y de diversas naves para el almacenamiento de la producción. El asentamiento poseyó asimismo un trapetum circular con muela troncocónica de piedra caliza para la molienda del cereal y una zona alfarera con tres hornos destinados a la fabricación de materiales de construcción y de cerámica de uso doméstico.

La pars rustica de la villa se articuló en torno a un gran patio cuadrado en el que una red de canalizaciones sirvió para la distribución del agua procedente de una cisterna asociada a un pozo. Un gran edificio cuadrangular, con tres alas perimetrales y estancias abiertas a este patio, albergó cuadras, establos, almacenes y dependencias destinadas al alojamiento de los trabajadores de la explotación. Otra construcción menor, de planta rectangular compartimentada en tres naves longitudinales, albergó tal vez un horreum para el cereal.

Las reformas acometidas a inicios del siglo III dC no afectaron en lo esencial el esquema primitivo de la villa, que en conjunto debía conservarse en perfecto estado. Por ello en la residencia principal se limitaron a la modificación del sistema de ingreso y a la creación de un hortus adosado a su costado occidental. En el torculario se instaló un sistema de doble prensa que fue destinado con toda probabilidad a la producción de aceite y, en el edificio de cuadras, se compartimentaron los espacios interiores, creando una serie de estancias repartidas regularmente por toda la planta. En el patio de servicio de los baños se ocupó la franja norte por medio de cobertizos apoyados sobre su muro de cierre. En las nuevas fábricas se emplearon sillarejos trabados con tierra que se enfoscaron exteriormente con cal y se pavimentaron las nuevas estancias con capas de mortero de escasa consistencia o bien con tierra compactada.

La construcción, a mediados de ese mismo siglo, de una nueva instalación de prensado en el ángulo sudoeste de la villa manifiesta la capacidad inversora de su propietario. Se destinó probablemente a las manufacturas vinícolas y su construcción supuso la demolición de parte del vallado perimetral original. A este mismo momento corresponde también el establecimiento, en el patio de servicio del balneum, de un ingenio para moler cereal, que determinó el desvío de su sistema primitivo de cloacas, así como la reconstrucción, desde prácticamente sus cimientos, de algunas de las estructuras de la pars rustica que se encontraban ya arruinadas. Para todo ello se emplearon muros de opus vittatum rematados en los extremos con grandes bloques escuadrados.

Las trasformaciones de finales del siglo III dC supusieron la ampliación de la residencia principal hacia el oeste con una nueva ala de carácter privado, ocupando parte del hortus precedente. También se procedió a la reparación de la natatio, a la instalación de unas pequeñas letrinas que aprovecharon su desagüe y a la construcción de un edificio de nueva planta adosado a la valla norte del patio de servicio de las termas. Para las nuevas estructuras se utilizaron mampuestos y materiales diversos de reempleo que se trabaron con mortero de cal.

Hasta el abandono final del asentamiento a inicios del siglo v dC, la actividad constructiva se redujo a estructuras de escasa entidad que se apoyaron en edificios anteriores, 


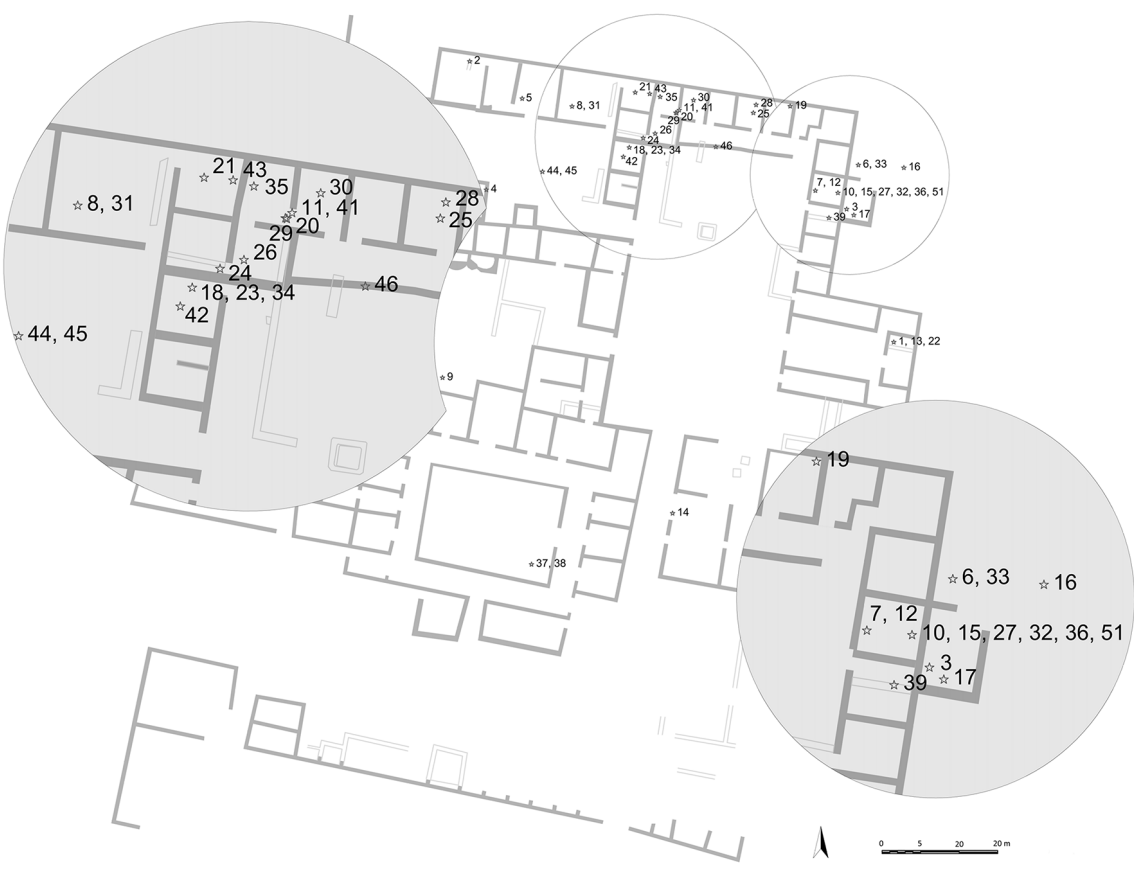

Figura 3. Plano de localización de los hallazgos monetarios en la villa del Pou de la Sargueta. La numeración corresponde a la del catálogo (elaboración: I. Hortelano Uceda).

ocupando generalmente espacios que en origen quedaban al aire libre. Se desconoce si hasta ese momento la vivienda principal continuó aún en uso o bien había sido ya abandonada, pero lo cierto es que la amortización de los desagües del balneum a mediados de la cuarta centuria demuestra la pérdida definitiva del uso balneario en la villa.

\section{Los hallazgos monetarios y su contexto arqueológico $^{2}$}

Las tres campañas de excavación desarrolladas en la villa del Pou de la Sargueta han proporcionado un total de cincuenta hallazgos monetarios (más un botón) de los que solo uno se considera descontextualizado, seis proceden de niveles superficiales y el resto, de contextos arqueológicos bien documentados (fig. 3 y tab. I). De estos, una pieza se

2. Cada moneda se asocia a un número de inventario asignado en el Museu de Prehistòria de València, a una unidad estratigráfica registrada en el proceso de excavación y a un código que representa el punto en que se produjo su hallazgo (vid. catálogo). 
Tabla I. Cuadro sinóptico de los contextos constructivo, estratigráfico, numismático y cerámico en relación con el catálogo

\begin{tabular}{|c|c|c|c|c|c|}
\hline \multicolumn{2}{|c|}{ Contexto estratigráfico } & \multicolumn{3}{|c|}{ Contexto numismático } & \multirow{2}{*}{$\begin{array}{l}\text { Contexto cerámico } \\
\text { Tipología u observaciones }\end{array}$} \\
\hline Cronología & U.E. & N..$^{\circ}$ en Catálogo & Emperador & Cronología (dC) & \\
\hline $\begin{array}{l}\text { Flavia } \\
69-96 \mathrm{dC}\end{array}$ & 1626 & 21 & Póstumo & $259-269$ & $\begin{array}{l}\text { Fuera de contexto. La moneda se encontró en una fosa } \\
\text { excavada en un nivel correspondiente a la primera fase } \\
\text { constructiva que no aportó materiales significativos. }\end{array}$ \\
\hline $\begin{array}{l}\text { Antonina } \\
96-192 \mathrm{dC}\end{array}$ & 1602 & $\begin{array}{l}47 \\
48\end{array}$ & $\begin{array}{l}\text { Posibles sestercios } \\
\text { SS. ॥I-III dC }\end{array}$ & & TSH (Drag 15/17, Drag 27 y Drag 37); Afr Cocina (H23B). \\
\hline \multirow[t]{2}{*}{$\begin{array}{l}\text { Severa } \\
193-235 \mathrm{dC}\end{array}$} & 1603 & 2 & Emisión anónima & $81-161$ & $\begin{array}{l}\text { TSH } 8 \text { (Drag 44); TSAfr A (H3C, H8A); Afr Cocina (Lamb } \\
\text { 9a/Hayes 27, H197, Ostia II/302). }\end{array}$ \\
\hline & 1795 & 39 & Adriano & $117-138$ & TSH 8 (Drag 15/17); Afr Cocina (H197, Ostia II/302). \\
\hline ca. $250 \mathrm{dC}$ & $\begin{array}{l}1257 \\
1306\end{array}$ & $\begin{array}{r}9 \\
14\end{array}$ & $\begin{array}{l}\text { Clodio Albino } \\
\text { Galieno }\end{array}$ & $\begin{array}{r}195 \\
253-268\end{array}$ & No aportaron materiales cerámicos significativos. \\
\hline \multirow[t]{30}{*}{$\begin{array}{l}\text { Finales s. III y s. } \\
\text { IV dC }\end{array}$} & 1176 & 30 & Claudio II & $268-270$ & $\begin{array}{l}\text { Moneda escondida en una pequeña fosa excavada sobre } \\
\text { un suelo de tierra que contenía, como material más } \\
\text { significativo, dos fragmentos de cocina africana Ostia I/261. }\end{array}$ \\
\hline & 1224 & 8 & Lucila & $163-164$ & $\begin{array}{l}\text { TSH (Drag 15/17, Drag 27); TSAfr A (Lamb 2a, Lamb 3b1, } \\
\text { H3A, H15); TSAfr C (H50A-Lamb } 40 \text { bis); TSAfr D (H54, }\end{array}$ \\
\hline & & 31 & Quintilo & 270 & $\begin{array}{l}\text { H58B); Afr Cocina (Lamb 9a/Hayes 27, H23B, H181, } \\
\text { H182, H197, Ostia IV/61); Ánfora africana sin forma. }\end{array}$ \\
\hline & 1601 & 5 & Elio & $101-138$ & $\begin{array}{l}\text { TSH (Drag 15/17, Drag 37); Afr Cocina (Ostia l/270, } \\
\text { H197). }\end{array}$ \\
\hline & 1637 & 10 & Gordiano III & $243-244$ & TSAfr C sin forma; Afr Cocina (Ostia I/261). \\
\hline & & 15 & Galieno & $253-268$ & \\
\hline & & 27 & Imitación Tétrico || & post 274 & \\
\hline & & 32 & Claudio II & $268-270$ & \\
\hline & & 36 & Tácito & $275-276$ & \\
\hline & & 51 & Botón & S. II (?) & \\
\hline & 1638 & 6 & Elio & 137 & No aportó materiales cerámicos significativos. \\
\hline & & 16 & Galieno & $253-268$ & \\
\hline & & 33 & Claudio II & $268-270$ & \\
\hline & 1661 & 44 & AE3 frustro & $355-363$ & TSAfr D (H59A); Afr Cocina sin forma. \\
\hline & 1669 & 24 & Divo Claudio & post 270 & No aportaron materiales cerámicos significativos. \\
\hline & 1674 & 45 & $\begin{array}{l}\text { AE3 } 0 \\
\text { antoniniano frustro }\end{array}$ & SS. III-IV & \\
\hline & 1726 & 18 & Galieno & $253-268$ & \\
\hline & & 23 & Divo Claudio & post 270 & \\
\hline & & 34 & Claudio II & $268-270$ & \\
\hline & 1745 & 20 & Salonina & $260-268$ & TSAfr A (H15); TSAfr C (H50A-Lamb 40 bis); TSAfr D \\
\hline & & 29 & $\begin{array}{l}\text { Imitación } \\
\text { antoniniano }\end{array}$ & S. III (?) & $\begin{array}{l}\text { (H59A); Afr Cocina (H23B, H181, H182, H197, Ostia } \\
\text { I/261, Ostia IV/61). }\end{array}$ \\
\hline & & 35 & Aureliano & $270-275$ & \\
\hline & 1757 & 25 & Divo Claudio & post 270 & No aportaron materiales cerámicos significativos. \\
\hline & & 28 & Imitación Tétrico || & post 274 & \\
\hline & 1799 & 19 & Galieno & $260-268$ & \\
\hline & 1111 & 7 & Lucila & $164-166$ & TSAfr D (H50, H54); Afr Cocina (H23A, H193, Ostia I/261). \\
\hline & & 12 & Galieno & $160-261$ & \\
\hline & 1155 & 49 & $\begin{array}{l}\text { Posible as } \\
\text { ss. ॥- III dC }\end{array}$ & & TSAfr D sin forma. \\
\hline & 1049 & 11 & Gordiano III & $243-244$ & $\begin{array}{l}\text { TSAfr C (H50A-Lamb } 40 \text { bis); TSAfr D (H50, H58A, H58B); } \\
\text { Afr Cocina (H23a, H181/193, H193, H197, Ostia I/261, }\end{array}$ \\
\hline & & 43 & Antoniniano & S. III & Ostia IV/61). \\
\hline
\end{tabular}




\begin{tabular}{|c|c|c|c|c|c|}
\hline \multicolumn{2}{|c|}{ Contexto estratigráfico } & \multicolumn{3}{|c|}{ Contexto numismático } & \multirow{2}{*}{$\begin{array}{l}\text { Contexto cerámico } \\
\text { Tipología u observaciones }\end{array}$} \\
\hline Cronología & U.E. & N. ${ }^{\circ}$ en Catálogo & Emperador & Cronología (dC) & \\
\hline \multirow{6}{*}{$\begin{array}{l}\text { SS. IV-v dC } \\
\text { y abandono }\end{array}$} & 1230 & 37 & Constancio II & $355-361$ & No aportaron materiales cerámicos significativos. \\
\hline & & 38 & Nepociano & 350 & \\
\hline & 1295 & 1 & Domiciano & $81-96$ & \\
\hline & & 13 & Galieno & $265-267$ & \\
\hline & & 22 & Divo Claudio & post 270 & \\
\hline & 1641 & 17 & Galieno & $260-268$ & \\
\hline \multirow[t]{5}{*}{ Nivel superficial } & 1000 & 3 & Adriano & $134-138$ & \\
\hline & 1008 & 40 & As & s. III & \\
\hline & & 41 & Antoniniano frustro & s. III & \\
\hline & 1214 & 26 & Claudio II & $268-270$ & \\
\hline & & 46 & $\begin{array}{l}\text { AE3 o } \\
\text { antoniniano frustro }\end{array}$ & SS. III-IV & \\
\hline \multirow[t]{2}{*}{ Reciente } & 1042 & 42 & Antoniniano frustro & s. III & \\
\hline & & 50 & Peseta & 1937 & \\
\hline Sin contexto & - & 4 & Adriano & $125-128$ & \\
\hline
\end{tabular}

recuperó en el relleno de una zanja contemporánea, cinco corresponden a niveles que se relacionan con el abandono definitivo del asentamiento a inicios del siglo $\mathrm{v} \mathrm{dC}$, cinco al último momento de ocupación de la villa durante el siglo Iv dC, 26 a la fase desarrollada tras las reformas acometidas a finales del siglo $\mathrm{III} \mathrm{dC}$, dos a actividades fechadas a lo largo de la segunda mitad del siglo III dC, y las cuatro restantes a momentos anteriores. La única pieza cuyo contexto no se conoce es un as de Adriano acuñado en Roma entre 125 y 128 dC (n. ${ }^{\circ} 4$ del catálogo), recuperada casualmente en 2006 sobre la esquina noreste del praefurnium del balneum, al margen de la intervención arqueológica.

Las monedas inventariadas con los $n .{ }^{o s} 3,17,26,40,46$ y 48 proceden de niveles superficiales o de estratos alterados por las labores agrícolas más recientes, tras el desfonde de los antiguos viñedos existentes en la partida del Pou de la Sargueta para su conversión en huertos de cítricos. Se trata de un sestercio de Adriano acuñado entre los años 134138 dC, un antoniniano de Galieno de 265 dC, un antoniniano de imitación hispánica de Claudio II, un as sin identificar (quizá de Adriano, datado durante el trienio 132-134 dC), otro as prácticamente descompuesto y una peseta de la II República Española. Por otra parte, el antoniniano frustro $n .^{\circ} 42$ (quizás una imitación), con busto radiado en el anverso, que pertenece a una emisión de la segunda mitad del siglo III dC, y la n. ${ }^{\circ} 47$, un cospel descompuesto con módulo de sestercio, aparecieron en el relleno de la zanja de suministro de agua que propició el hallazgo de la villa en 2004.

Tres de las cinco monedas aparecidas en contextos de abandono proceden del edificio que se interpreta como destinado al almacenamiento del cereal, en el lateral oriental de la pars rustica de la villa. Se trata de un as de Domiciano acuñado en Roma (moneda n. ${ }^{\circ} 1$ del catálogo), un antoniniano de Galieno acuñado en Roma entre 265 y 267 dC (catálogo n. ${ }^{\circ}$ 13) y una imitación hispánica de un antoniniano de Divo Claudio II, de acuñación pos- 
terior a $270 \mathrm{dC}$ (moneda n. ${ }^{\circ} 22$ ). Todas ellas se recuperaron en un relleno con abundantes restos cerámicos que amortizaba las estancias que compartimentaban el fondo del edificio. Las otras dos monedas fueron halladas entre los niveles de derrumbe del tejado del atrio, en su esquina sudoriental, junto a numeroso material latericio y restos de enlucido de cal. Ambas son mayorinas; la n. ${ }^{\circ}$ 37, de Constancio II, y la n. ${ }^{\circ} 38$, de Nepociano (esta última acuñada en Roma sobre $350 \mathrm{dC}$ ).

Los contextos de ocupación tardorromanos aportaron cinco monedas. Dos se recuperaron en un gran relleno de tierra arcillosa de color rojizo, con abundantes placas de pavimento y fragmentos de tegulae, que nivelaba las habitaciones del ala norte del edificio de la pars rustica. Una de ellas, la n..$^{\circ} 11$, es un sestercio de Gordiano III acuñado en Roma entre 243 y 244 dC. La otra, la n. ${ }^{\circ} 43$, resultó frustra, con un posible busto con corona radiada en el anverso. Las monedas n. ${ }^{\circ} 7$, un as de Lucila, y n. ${ }^{\circ} 12$, un antoniniano de Galieno de acuñación romana fechado hacia 260-261 dC, aparecieron en un relleno similar en el ala este del mismo edificio, y la n. ${ }^{\circ} 49$, un cospel descompuesto si bien de módulo as, en el interior de un muro de fábrica muy descuidada y construido en la esquina noroeste del patio.

El mayor número de hallazgos monetarios corresponde a la ocupación situada tras la ampliación y las grandes reformas fechadas a finales del siglo III dC, y se concentran en la franja norte de la pars rustica. En esta zona se identificaron hasta ocho pequeños depósitos monetarios localizados en los suelos de las habitaciones, generalmente en sus esquinas o junto a sus paredes, pero también en su centro. En una de las estancias del ala oeste se halló un conjunto de tres monedas, un antoniniano de Galieno (n. ${ }^{\circ} 18$ ) y dos de Claudio II, si bien uno de ellos es una imitación hispánica Divo Claudio II (monedas n. ${ }^{\text {os }} 34$ y 23 , respectivamente), escondidas en el extremo norte, en un nivel de tierra arcillosa suelta, muy fina, de color marrón rojizo, que constituía el piso. En la misma habitación, pero algo más hacia el centro, se localizó un AE3 de Constancio II o Juliano II, moneda n. ${ }^{\circ} 44$ del catálogo, y en un relleno semejante, pero con manchas negruzcas de cenizas (fig. 4).

En la esquina suroeste de la habitación vecina se halló otra imitación hispánica de un antoniniano de Divo Claudio II (moneda n. ${ }^{\circ} 24$ ), oculta asimismo en el suelo, una capa de tierra roja de textura arenosa con nódulos de cal y algunas gravas. El hallazgo de un antoniniano de Póstumo (moneda n. ${ }^{\circ} 21$ ) en la habitación que ocupa la esquina noroeste del edificio de la pars rustica constituye una intrusión, pues se produjo en una preparación horizontal de piedras de una fase anterior, probablemente como consecuencia de la excavación, desde el nivel del pavimento de tierra superpuesto, de una fosa que no fue identificada en la intervención.

Los hallazgos en la segunda estancia del ala norte se localizaron junto a su pared oeste y en el ángulo sudeste, el opuesto a su entrada: se recuperaron otros tres antoninianos, uno de Salonina acuñado en la ceca de Mediolanum entre 260 y 268 dC, otro de «imitación bárbara" y el tercero de Aureliano, probablemente acuñado en Mediolanum hacia los años 270-275 dC (monedas n. ${ }^{\text {os }} 20,29$ y 35, respectivamente), tapados todos ellos con tierra arcillosa roja y suelta. 


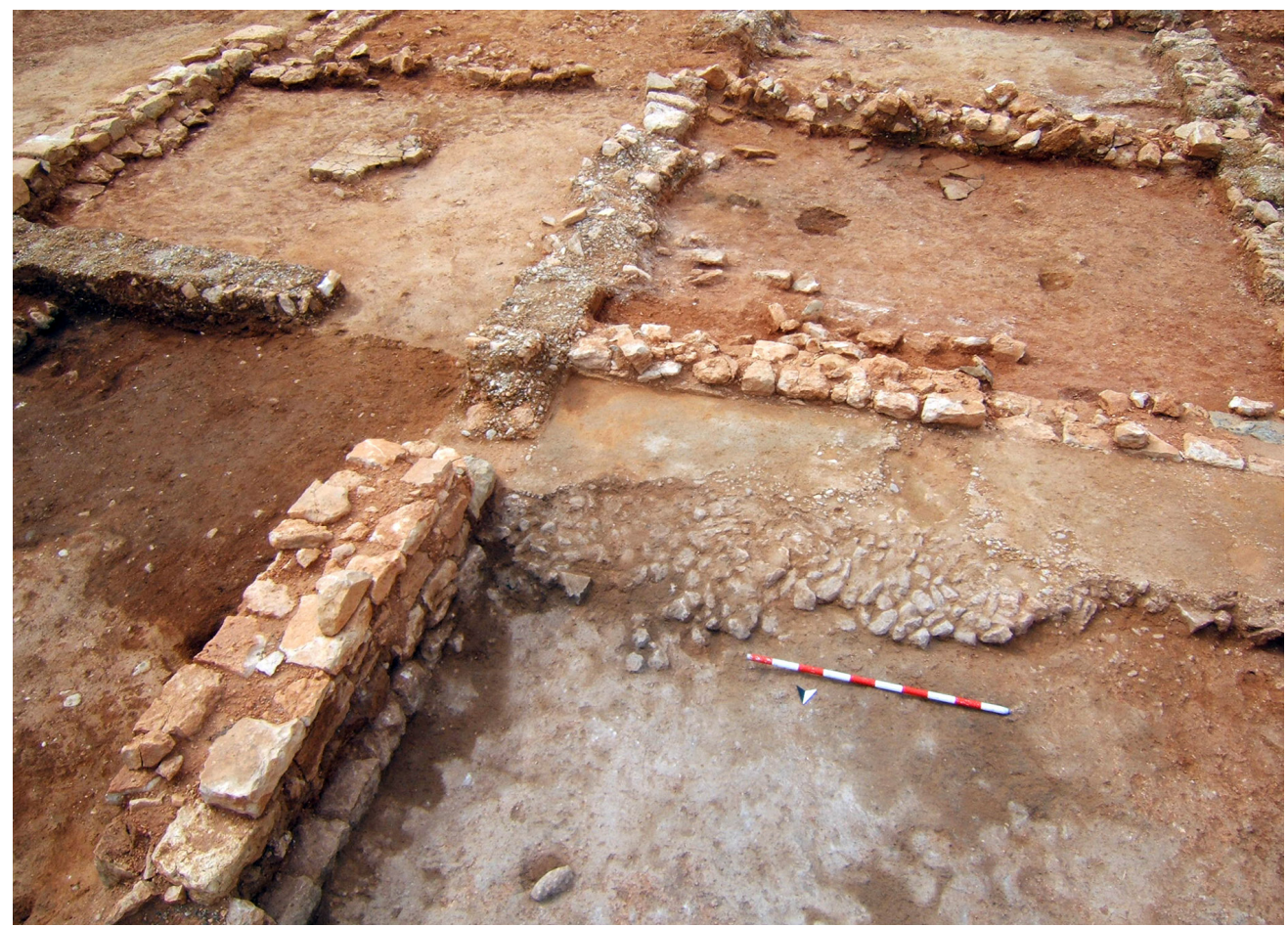

Figura 4. Vista desde el norte de las estancias del ala occidental del edificio de la pars rustica en las que se documentaron diversos hallazgos monetarios (imagen: I. Hortelano Uceda).

En el cuarto situado inmediatamente al este se halló un antoniniano de Claudio II (moneda n. ${ }^{0} 30$ ) oculto bajo su nivel de circulación, en el centro de la habitación. También eran antoninianos las monedas escondidas en medio de una de las habitaciones centrales de esta ala norte, dentro de un relleno arcilloso rosado muy homogéneo y fino. La n. ${ }^{\circ} 25$ del catálogo se trataba de una imitación hispánica de época de Divo Claudio II, mientras que la n. ${ }^{\circ} 28$ era una "imitación bárbara» del período de Tétrico I, tal vez emitida en Hispania o en la Gallia a finales del siglo III dC.

La habitación contigua proporcionó un peculiar ejemplo de escondite en el que tan solo se conservaba una única pieza, quizás olvidada al recuperar su propietario el monedero. Una tegula completa dispuesta horizontalmente servía de fondo a una fosa excavada en un piso de tierra compactada. Sobre ella, un relleno muy suelto y arenoso de color pardo contenía un antoniniano de Galieno acuñado en Roma entre 260 y 268 dC (moneda n. ${ }^{\circ} 19$ ).

El depósito más cuantioso fue el documentado en el ala occidental de este mismo edificio, donde se recuperó un conjunto de cinco antoninianos y un botón de bronce. Se hallaron en el interior de un pequeño hoyo excavado en un piso de mortero, junto a la pared este de la estancia, tapados con tierra arcillosa rojiza muy suelta. El lote estaba 
formado por una pieza de Gordiano III, acuñada en Roma entre 243 y 244 dC (moneda n. ${ }^{\circ} 10$ ); otra de Galieno (n. $\left.{ }^{\circ} 15\right)$; una «imitación bárbara» del período de Tétrico I, de acuñación posiblemente hispana o gala ( $\mathrm{n}^{\circ} 27$ ); otra de Claudio II, acuñada en Roma entre 268 y 270 dC (n. ${ }^{\circ} 32$ ); otra de Tácito, de emisión también romana, de los años 275-276 dC (moneda n. $\left.{ }^{\circ} 36\right)$, y un pequeño botón de bronce (n. $\left.{ }^{\circ} 51\right) .^{3}$

Correspondiente al último momento de uso de esta zona del edificio antes de su definitiva transformación a mediados del siglo IV dC hay un AE3 de Constancio II o Juliano II (n. $\left.{ }^{\circ} 44\right)$ hallada, junto a otros pocos objetos, sobre el pavimento de tierra de la estancia situada en el ángulo noroeste. También son de ese tiempo las piezas halladas en los vertidos de materia orgánica negruzca localizados a la salida del desagüe que atravesaba su patio: un as de Elio (moneda n. ${ }^{\circ} 6$ ) y dos antoninianos, uno de Galieno (n. ${ }^{\circ}$ 16) y otro de Claudio II acuñado en Roma (n. ${ }^{\circ} 33$ ), así como un segundo as de Elio recuperado en los rellenos que amortizaban la instalación destinada a la molienda del cereal (moneda n. ${ }^{\circ}$ ) .

Los hallazgos monetarios de esta fase se completan con dos monedas procedentes del vertedero de cenizas que, a lo largo de la primera mitad del siglo III dC, ocupó parte del antiguo patio de servicio del balneum, coincidiendo con su último momento de uso. Se trata de un as de Lucila emitido en Roma bajo el reinado de Marco Aurelio (moneda n. ${ }^{\circ} 8$ ) y de un antoniniano de Quintilo acuñado en Roma hacia $270 \mathrm{dC}$ (moneda n. ${ }^{\circ} 31$ ).

Por lo que respecta a fases anteriores, los hallazgos monetarios resultan significativamente más escasos y se limitan a un antoniniano de Galieno emitido en Roma, que se halló en el umbral abierto a inicios del siglo III dC en la pared oeste del torculario (moneda n. ${ }^{\circ}$ 14), y a un as de Clodio Albino de la ceca de Roma acuñado en 195 dC, que apareció sobre el piso de tierra y gravas del patio privado situado entre el balneum y la residencia principal; muy próxima a esta, junto a su acceso (moneda n. ${ }^{\circ}$ 9), se halló también un as frustro del siglo II dC (n. $\left.{ }^{\circ} 39\right)$ y un cuadrante de las series anónimas de Domiciano a Antonino Pío (moneda n. ${ }^{\circ} 2$ ) procedentes de sendas nivelaciones de época severa, en el ala este del Edificio A y en el extremo noroccidental del patio de servicio del balneum, respectivamente. Por último se exhumaron dos cospeles descompuestos, imposibles de identificar, pero con módulo de sestercio, hallados en un relleno de época antonina de ese mismo patio (monedas n. ${ }^{\text {os }} 47$ y 48 ).

\section{Análisis numismático}

El conjunto total exhumado asciende a las 50 piezas: una moneda del siglo I dC (2\%), diez del II dC (20\%), veintiuna del III dC (44\%), ocho imitaciones a caballo entre el III y el IV dC $(16 \%)$, tres del IV dC (6\%), una contemporánea $(2 \%)$ y cinco frustras ( $13 \%)$ — dos parecen corresponderse con módulos tipo AE3/antoniniano y las demás podrían ser

3. Se incluye en el presente catálogo debido a que se reconoció como tal tras la limpieza del material. 


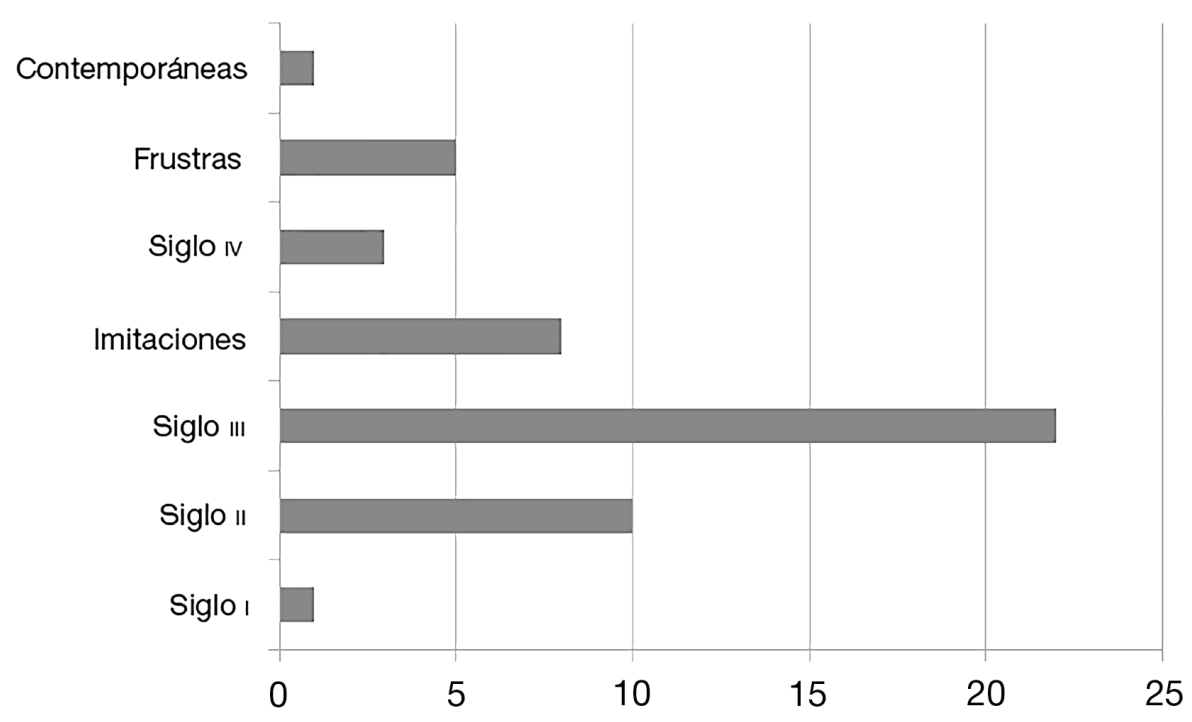

Figura 5. Histograma de ejemplares por siglo y/o categoría (elaboración: D. Martínez Chico).

dos sestercios y un as de los siglos II-III dC, respectivamente; vid. monedas n. ${ }^{\text {os }} 45-49$ - , sin olvidar el ya citado botón romano (n. $\left.{ }^{\circ} 51\right)$. Estas monedas forman un circulante menudo de metal bajo, perdido involuntariamente debido a su uso diario y/o cotidiano en la villa.

En general, durante las dinastías julioclaudia y flavia la masa monetaria se nutría fundamentalmente del binomio "denario/as». ${ }^{4}$ La primera moneda es la que más se atesoraba; la segunda, la que más se perdía, pero ambas monedas situadas dentro de los circuitos monetarios. Para el siglo i dC en el Pou de la Sargueta se ha contabilizado solo un as de Domiciano (moneda n. ${ }^{\circ}$ l) muy desgastado y que viene a coincidir con los inicios de la villa romana en la primera mitad del siglo i dC.

El siglo II dC supone un cambio drástico, pues la villa experimenta una importante inyección de moneda importada desde la ceca de Roma. Según los datos arqueológicos, esta etapa del Pou de la Sargueta es la más floreciente del asentamiento y testigo de las principales delimitaciones constructivas de la residencia. No obstante, los datos numismáticos permiten matizar esta aseveración: atendiendo a la evolución del numerario por siglos (fig. 5), en el Pou de la Sargueta resulta abrumadora la gran mayoría de antoninianos del III dC, propia de una sociedad altamente monetizada. Estos momentos coinciden con nuevas reformas y evidencian que la propiedad tiene aún recursos suficientes para acometerlas, pues alcanzan la totalidad del establecimiento. Cuantitativa y cualitativamente, estos datos parecen corregir, en cierto modo, los anteriores datos arqueológicos, que apuntaban que el máximo florecimiento de la vida en la villa se situaba en el siglo II dC.

4. Visiones globales sobre el comportamiento, la historia y la política monetaria pueden encontrarse en varias obras, como las de Crawford (1986), Burnett (1987 y 1991), Howgego (1995), Harl (1996) y González García (2011a). 
Sea como fuere, es importante destacar que si bien el siglo II dC se suele caracterizar como una etapa dominada por el denario, en detrimento del sestercio, dupondio y as, estas últimas monedas, especialmente el as, resultan muy abundantes en el Pou de la Sargueta, y se contabilizan: hasta un cuadrante (moneda $n .^{\circ} 2$ ), un sestercio (moneda n. ${ }^{\circ}$ 3) y seis ases de época antonina (monedas n. ${ }^{\text {os }} 4-9$ ). En cambio, el grueso monetal del siglo III dC se compone en exclusiva de antoninianos (monedas n. ${ }^{\text {os }} 12-21$ y 30-36). La reforma monetaria impuesta por Caracalla en ca. 215 dC masificó el uso de la moneda en toda la sociedad romana, con la sustitución del ya de por sí paupérrimo denario, cuyo contenido argénteo llegaba a veces al 25 \% (Sydenham, 1919: 131-135; Callu, 1969: 197; Burnett, 1987: 48-49; Ripollès Alegre, 2002: 205-206). Con la introducción del antoniniano se aumentó el peso de la moneda a menos del doble del denario —es decir, en torno a los $5 \mathrm{~g}$-, aunque el valor fiduciario fuera superior al valor de su metal. Inicialmente, la introducción de esta moneda debió ser impopular, tal y como ilustran distintos intentos de su supresión por emperadores tan conservadores como Macrino, Heliogábalo, Alejandro Severo y Maximino I (Callu, 1969: 197 y 476-477; Burnett, 1987: 48-49); después de todo, el antoniniano vino para desaparecer, aunque se convirtió en la moneda base hasta las diversas reformas del siglo IV dC.

Los antoninianos de Galieno (260-268 dC) (monedas n. $\left.{ }^{\text {os }} 12-20\right)$ y Claudio II (268270 dC. (monedas n. ${ }^{\text {os }}$ 30-34) son muy abundantes en el Pou de la Sargueta: se han recogido nueve antoninianos de Galieno, que incluyen uno de Salonina, y cinco de Claudio II. Se trata de un comportamiento muy bien documentado en cualquier yacimiento del Mediterráneo occidental o el que nos ocupa, las costas tarraconenses (Lledó Cardona, 2007: 291). Hoy se admite que la deriva inflacionista de este momento y la implosión de estos tipos de antoninianos saturaron la economía de finales del siglo III dC, pues se trataba de unas piezas prácticamente en cobre y no ya en vellón alto. A partir del reinado de Galieno, el aparente blanqueado de plata era producido tras una sumersión en ácido que permitía la eliminación del cobre, presente en la superficie de dichos antoninianos y dándoles una apariencia de plata (Callu, 1969: 214-218).

Constituyen un bloque homogéneo las imitaciones halladas en el Pou de la Sargueta y que podemos diferenciar en «imitaciones hispánicas», tomando prototipos de Divo Claudio II (acuñados bajo los mandatos de Quintilo y Aureliano sobre $270 \mathrm{dC}$ ), con cinco monedas (monedas n. $\left.{ }^{\text {os }} 22-26\right),{ }^{5}$ y las «gálicas», tomando modelos de Tétrico I y/o II (monedas n. ${ }^{\text {os } 27-29)}$. Ambas producciones locales se han querido ver en relación con una carestía de numerario manifiesta en zonas rurales de Hispania y la Gallia. Su perduración en el registro arqueológico parece avanzar hasta el siglo v dC, como sugieren algunos tesorillos norteafricanos (Callu, 1974: 551-552) e importantes yacimientos arqueológicos de Hispania (e.g., Bost et al., 1987: 76). El volumen de imitaciones de los siglos III-IV dC para

5. En nuestro caso, dos con águila frente a dos con altar, si bien la quinta frustra. De manera particular, las proporciones por reversos entre las monedas Divo Claudio II están también casi igualadas en yacimientos hispanos como Conimbriga, Tarraco, Grau Vell, Clunia y Belo, aunque el tipo altar suele ser más frecuente (sobre un 60 \%), como bien ha recogido Gozalbes (1999: 75-76). 
el litoral tarraconense nos es desconocido, pero debió ser muy alto a lo largo del Levante español, como demuestra el gran número de ellas y halladas en un yacimiento sistemáticamente estudiado como Grau Vell (Sagunto, València) (Gozalbes, 1999: 72-77 y 88-89), sin olvidar otros enclaves rurales (Lledó Cardona, 2007: 294; recientemente, Martínez Chico y González Fernández, 2018).

Por ello el fenómeno de la imitación se inicia a finales del siglo III dC, se convierte en toda una constante a lo largo del siglo IV dC, y dicho numerario perdura hasta la siguiente centuria. Son muchas las hipótesis que a este respecto se han barajado sobre las causas reales y sus lugares concretos de emisión. Bastien (1985: 146) propone que simplemente talleres auxiliares, surgidos en todo el Occidente, se encargaron de emitir dichas monedas, mientras que Cepeda Ocampo (1991: 378-379) apunta su origen concreto en la Gallia y venidas a Hispania mediante los cauces monetales de aprovisionamiento. No deben considerarse tampoco falsificaciones al uso ( $c f$. Grierson, 1956), más aún cuando los mismos usuarios de esta moneda las utilizaran reconociendo su valor inferior e, incluso, se tratara de una actividad encubierta o tolerada por necesidad desde el mismo poder público (Harl, 1996: 167-171; Ripollès Alegre, 2002: 209-210; Martínez Chico, 2014: 163-164). La equiparación de la moneda de imitación como oficial durante el siglo IV dC y los albores del v puede ser constatada mediante algunos tesoros hispanos, como el de la plaza de Sant Miquel (Barcelona), que contiene un 22 \% de imitaciones y el resto, oficial (Marot Salsas, 1994: 385-387). También muy revelador es el gráfico de Pou de la Sargueta (fig. 5): se contabilizan para el siglo IV dC solo tres monedas, y dos de ellas catalogables (monedas n. ${ }^{\text {os }}$ 37-38), lo que plantea que la casi supresión del suministro en dicho siglo se viera aliviada con las imitaciones.

Desde el punto de vista meramente numismático destacan ciertas piezas, como el cuadrante anónimo con Marte (moneda n. ${ }^{\circ}$ ), cuyas series son bastante complejas al desconocerse el carácter y la cronología de sus emisiones. Tal es el desconocimiento de dichas monedas que se vienen datando entre los reinados de Domiciano y Antonino Pío (ca. 81-161 dC); a muchos de los dioses, como Júpiter, Tíber y el mismo Marte, representados en los anversos, se les han atribuido rasgos similares a los de los mandatarios romanos. El estudio de cuños más destacado acerca de estas piezas es el realizado por el belga Van Heesch (1979) en una tesis aún inédita. Descartando hoy día la consideración de téseras, Mattingly y Sydenham (1926: 214-215) decían que algunas de estas piezas pudieran estar relacionadas con distritos mineros y que las monedas se utilizaron como moneda divisionaria, ante la carestía de dicho numerario cotidiano. Un ejemplar proveniente de Cástulo (Not in RIC, si bien tipo 534/535, de Van Heesch, 1979: 250) ha reforzado esta hipótesis; sea cierta o no, la gran mayoría de estas monedas demuestra cierto carácter republicano en sus iconografías, tal vez en clara alusión a su poder emisor (Martínez Chico, 2016), pero parece tratarse de un motivo iconográfico meramente reminiscente. Tesis y antítesis aparte, estas monedas pueden considerarse como cuadrantes y semises devaluados; sin duda, un tipo de moneda ajustada para los ambientes más humildes de la era antonina. 

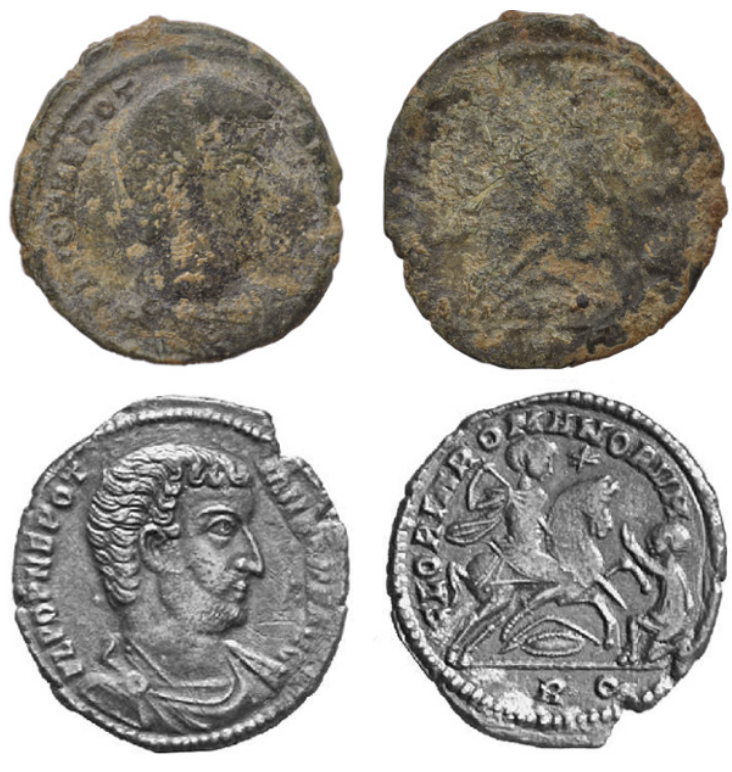

Figura 6. AE2 de Nepociano — RIC VIII 200 (moneda n. $\left.{ }^{0} 38\right)$ - acuñada en Roma entre el 3 y el 30 de junio de $350 \mathrm{dC}$ frente a otra de gran conservación proveniente de Numismatik Lanz München, subasta 100, lote 581 (20/11/2000).

Otra pieza excepcional es el raro nummus de Nepociano (moneda n. ${ }^{\circ}$ 38, fig. 6), acuñado en Roma (350 dC). Las monedas pertenecientes a usurpadores romanos y con menos de un año de duración al mando son raras de ver y mucho menos en yacimientos; una vez vencidos estos personajes, la gran mayoría de sus piezas era rápidamente sustraída del circuito para la fabricación de nuevas monedas o, en su caso y ante la falta de medios, las autoridades competentes se decantaban por la simple reacuñación, como pasó con el también usurpador Magnencio con la sustracción de monedas acuñadas por Constante, hermano de Constancio II (Moreno y Casanova, 2007). Esta situación se agravó flagrantemente con los años sucedidos por las guerras entre Constancio II y los usurpadores Magnencio y su César Decencio (350-353 dC), Vetranio (350 dC), Nepociano (350 dC) y Silvano (355 dC) (López Sánchez, 2000; Moreno Resano, 2009: 315-320; González García, 201 lb: 120). Los motivos de esta moneda en la costa levantina de Hispania parecen relacionarse con el mismo Constancio II. Una vez derrotado Nepociano y su cabeza puesta en una pica, el legítimo emperador tuvo que acantonar sus tropas en la Península Ibérica para arrebatar también el control de la diócesis hispana a Magnencio. En definitiva, una viva actividad militar desarrollada en Hispania entre los años 352 y 353 dC que parece explicar la importación misma de esta moneda, procedente de Roma y de la mano de algún soldado, a la villa romana del Pou de la Sargueta. Pero es preciso insistir en que, a tenor de su desgaste, la moneda de Nepociano se integró perfectamente en la circulación corriente.

La arqueología numismática del Pou de la Sargueta ha mostrado asimismo varias monedas asociadas a diferentes contextos. Así, destaca la U.E. 1637 con antoninianos de Gordiano III; Galieno, de imitación bárbara que sigue prototipos tetricoides; Claudio II y 
Tácito (monedas n. ${ }^{\text {os }} 10,15,27,32$ y 36), con la deducción de un estrato de finales del siglo III o principios del IV dC, por lo que suponemos que la moneda de imitación estaba en pleno uso. Idéntico comportamiento siguen las UU.EE. 1726, 1745 y 1757, con la mezcla de antoninianos de imitación Divo Claudio II y tetricoides con monedas oficiales de Galieno, Salonina, Claudio II y Aureliano. En cualquier caso, no se trataría de ocultaciones, sino de monederos en claros contextos tardíos de abandono. Esto nos permite comprobar que la escasa presencia de moneda del siglo iv dC se alivió en la villa con antoninianos del siglo III dC (imitaciones incluidas); prueba de su perduración en el registro monetario es el acusado desgaste que dichas piezas presentan en sus cospeles.

\section{Conclusiones}

No nos encontramos ante un numerario de carácter residual. Las monedas estudiadas del Pou de la Sargueta forman parte del circulante cotidiano, utilizado por el campesinado desde el siglo I al v dC. Para Bost (1992-1993), el gran defensor de la monetización rural, lejos de considerar las villae entes autárquicos y rentistas, estas estaban insertas en las grandes corrientes económicas. Simplemente el uso de las monedas y sus respectivos hallazgos, en el medio rural, pueden considerarse un triunfo del dominio liderado por las élites romanas. La hipótesis de que los consumidores de esta moneda menuda hallada en la villa se relacionen con campesinos y arrendatarios es, hoy por hoy, aceptada por la historiografía, aunque tal afirmación pueda ser objeto de matización, pues evidentemente la moneda menuda no solo fue utilizada por ese sector de la sociedad.

Hemos de recalcar que la causa fundamental se encuentra dentro de un proceso de producción y exportación de productos, donde el comercio actuó como el verdadero impulsor de la monetización en todo el Imperio romano (Howgego, 1995: 22-23). El campesinado, hasta entonces considerado al margen de los intercambios pecuniarios, se convirtió en agente de la monetización al abrirse el agro a la circulación monetaria (Bost, 1992-1993: 225).

Finalmente, hemos de tener en cuenta que los antoninianos, especialmente los devaluados, se producen en cantidades muy elevadas y, junto con sus imitaciones, inundaron los mercados y aumentaron exponencialmente el índice de pérdidas. Este ha sido el principal argumento a fin de prejuzgar el siglo III dC como una etapa decadentista y autárquica, en detrimento del resurgir de la vida cotidiana, y que precisamente se ha hecho coincidir con el principio del deterioro en muchas villae de Hispania (contra ello, vid. también Lewit, 2004 y Bowes, 2013: 194 y 218-219).

La numismática y, especialmente, su incidencia en la economía demuestran todo lo contrario: algo tan fácil como aceptar que, si la moneda inunda el mercado, no hay vuelta a una economía natural. En este sentido, son muchos los estudios que afirman con total razón la pervivencia de la economía monetaria hasta bien entrado el siglo vi dC (Marot Salsas, 2001). No solo eso, sino la existencia de una completa integración, gracias a una 
economía próspera, compleja y alejada de prejuicios decadentistas, lo cual no excluye reconocer coyunturas de crisis o diferencias cuantitativas y cualitativas (Cepeda Ocampo, 1996; Banaji, 2001: 39-88).

\title{
5. Catálogo de monedas
}

\author{
1. As de Domiciano (81-96 dC) \\ Anv.: Busto del emperador a derecha. \\ Rev.: Frustro. \\ Ceca/fecha: Roma. \\ Medidas: $12,48 \mathrm{~g} ; 18 \mathrm{~mm}$. \\ Ref.: - \\ MPV: 41912.
}

Procedencia: U.E. 1295, punto de hallazgo 027. Se recuperó en la segunda campaña de excavaciones junto con las monedas $n .{ }^{\text {os }} 13$ y 22 del presente inventario, en un relleno de tierra arcillosa rojiza que contenía abundante material cerámico y amortizaba las estancias situadas al fondo del Edificio C, horreum.

2. Cuadrante. Series anónimas de Domiciano a Antonino Pío (81-161 dC)

Anv.: Busto de Marte con casco, barbado y con coraza a derecha.

Rev.: S C a los lados de una coraza.

Ceca/fecha: Sin determinar, 81-161 dC.

Medidas: 2,82 g; $9 \mathrm{~mm}$.

Ref.: RIC II 19.

MPV: 41930.

Procedencia: U.E. 1603, punto de hallazgo 062. Apareció durante la tercera campaña de excavaciones en una nivelación de tierra marrón rojiza oscura con presencia de cenizas y carbones, vertida sobre un pavimento de tejas en la esquina NW del patio de servicio del balneum.

3. Sestercio de Adriano (117-138 dC)

Anv.: [HADRIANVS AVG COS III P P]. Busto desnudo de Adriano, laureado y drapeado a derecha.

Rev.: [HISPANIA o AEGYPTOS, en exergo S C]. Hispania o Egipto recostada a la izquierda, sosteniendo sistrum y descansando el codo sobre la cesta; a la izquierda, un pájaro ibis en la columna. Ceca/fecha: Roma, 134-138 dC.

Medidas: $26,23 \mathrm{~g} ; 26 \mathrm{~mm}$.

Ref.: RIC II $85 / 838$.

MPV: 41898.

Procedencia: U.E. 1000, punto de hallazgo 001. Se halló en la primera campaña de excavaciones en niveles superficiales de tierra removida por trabajos agrícolas junto a una gran balsa de riego.

4. As de Adriano (117-138 dC)

Anv.: [HADRIANVS AVG COS III P P]. Busto desnudo de Adriano, laureado y drapeado a derecha. 
Rev.: S C a los lados. Diana de pie hacia la izquierda, sosteniendo flecha en la mano derecha y arco, en la izquierda.

Ceca/fecha: Roma, 125-128 dC.

Medidas: 11,21 g; $17 \mathrm{~mm}$.

Ref.: RIC II 824.

MPV: 42334.

Procedencia: sin contexto, punto de hallazgo 070. Hallazgo casual producido al margen de la intervención arqueológica junto al praefurnium del balneum.

\section{As de Elio (10 - $138 \mathrm{dC})$}

Anv.: Busto barbado de Elio a derecha.

Rev.: Frustro.

Ceca/fecha: Roma, bajo Adriano.

Medidas: 10,97 g; $17 \mathrm{~mm}$.

Ref.: -

MPV: 41916.

Procedencia: U.E. 1601, punto de hallazgo 045. Se encontró durante la tercera campaña de excavaciones en la nivelación de un pavimento correspondiente a la fase de reformas acometidas a finales del siglo III o inicios del IV, que amortizaba una instalación de molienda de cereal junto a la cerca norte de la villa.

\section{As de Elio (10 - $138 \mathrm{dC})$}

Anv.: [L AELIVS CAESAR]. Busto barbado de Elio a derecha.

Rev.: [TR POT CO]S II / S C. Spes avanzando a izquierda con flor y sujetándose el vestido.

Ceca/fecha: Roma, 137 dC (bajo Adriano).

Medidas: 10,67 g; $15 \mathrm{~mm}$.

Ref.: RIC II 1067.

MPV: 41926.

Procedencia: U.E. 1638, punto de hallazgo 054. Esta moneda se halló en la tercera campaña, junto a la n. ${ }^{\circ} 33$ del presente catálogo y muy próxima a la n. ${ }^{\circ} 16$, en un vertido de tierra suelta limosa de color negruzco, con presencia de abundante materia orgánica, desaguando al exterior del Edificio A por una canalización procedente de su patio.

\section{As de Lucila (164-166 dC)}

Anv.: Busto drapeado de Lucila a derecha.

Rev.: Frustro.

Ceca/fecha: Roma, bajo Marco Aurelio.

Medidas: 8,45 g; $17 \mathrm{~mm}$.

Ref.: -

MPV: 41903.

Procedencia: U.E. 1111 , punto de hallazgo 009. Se encontró, junto con la moneda n. ${ }^{\circ} 12$ del catálogo, en una nivelación de arcilla roja clara en una de las habitaciones del ala este del Edificio A, pars rustica.

\section{As de Lucila (164-166 dC)}

Anv.: [LVCILLAE AVG ANTONINI AVG F]. Busto drapeado de Lucila a derecha.

Rev.: [VENVS]. Venus entronizada a izquierda y sosteniendo Victoria y cetro.

Ceca/fecha: Roma, 163-164 dC (bajo Marco Aurelio). 
Medidas: 8,08 g; $17 \mathrm{~mm}$.

Ref.: ¿RIC III 1774 ?

MPV: 41908.

Procedencia: U.E. 1224, punto de hallazgo 024. Se recuperó con la moneda n. ${ }^{\circ} 31$ del catálogo en el gran vertedero de cenizas que, durante el último momento de uso del balneum, ocupó gran parte de su patio de servicio.

9. As de Clodio Albino (193-197 dC)

Anv.: [D CLOD SEPT - ALBIN CAES]. Busto barbado de Clodio Albino a derecha.

Rev.: [COS II / S C]. Esculapio desnudo desde la cintura, de pie a la izquierda, sosteniendo un bastón alrededor del cual se envuelve una serpiente.

Ceca/fecha: Roma, $195 \mathrm{dC}$.

Medidas: $9,25 \mathrm{~g} ; 16 \mathrm{~mm}$.

Ref.: RIC IV-1 57.

MPV: 41911.

Procedencia: U.E. 1257, punto de hallazgo 026. Apareció sobre el piso de gravas y tierra batida del patio privado situado entre el balneum y la residencia principal, muy próxima a esta, junto a su acceso.

10. Antoniniano de Gordiano III (238-244 dC)

Anv.: IMP GORDIANVS PIVS FEL AVG. Busto radiado de Gordiano III drapeado y con coraza. Rev.: [VICTORIA AETERNA]. Mano apoyada en escudo y rama de palma y un cautivo a sus pies.

Ceca/fecha: Roma, 243-244 dC.

Medidas: 3,61 g; $16 \mathrm{~mm}$.

Ref.: RIC IV-2 156; Cunetio 286.

MPV: 41923.

Procedencia: U.E. 1637, punto de hallazgo 49. Fue hallada en la tercera campaña de excavaciones junto a las monedas n. ${ }^{\text {os }} 15,27,32,36$ y del botón $n .^{\circ} 51$ del presente catálogo, formando parte de un mismo conjunto. Las seis monedas se localizaron en el interior de un pequeño hoyo excavado en el pavimento de mortero de una de las habitaciones del ala este de la pars rustica, junto a la pared oriental de la estancia, que se encontraba relleno de tierra arcillosa rojiza muy suelta.

\section{Sestercio de Gordiano III (238-244 dC)}

Anv.: IMP GORDIANVS PIVS FEL AVG. Busto laureado de Gordiano III con coraza a derecha. Rev.: [P M TR P V COS] COS [II P P]. Emperador estante a derecha con globo y lanza portando de forma transversal.

Ceca/fecha: Roma, 243-244 dC.

Medidas: 19,20 g; $20 \mathrm{~mm}$.

Ref.: RIC IV-3 307.

MPV: 41900.

Procedencia: U.E. 1049, punto de hallazgo 004. La moneda se encontró junto a la n. ${ }^{\circ} 43$ en un gran relleno de tierra arcillosa de color rojizo, con abundantes placas de pavimento y fragmentos de tegulae, que nivelaba las habitaciones del ala norte del edificio de la pars rustica.

12. Antoniniano de Galieno (253-268 dC)

Anv.: GALLIENVS AVG. Busto radiado y barbado de Galieno a derecha. 

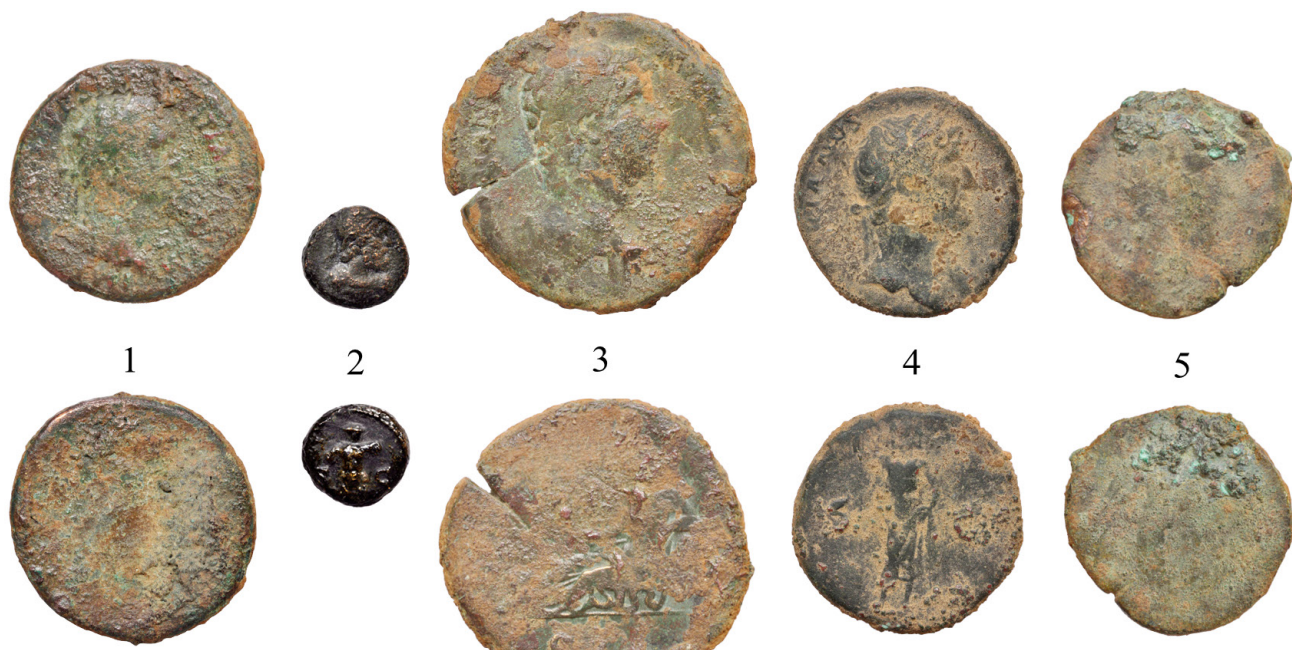

3

4
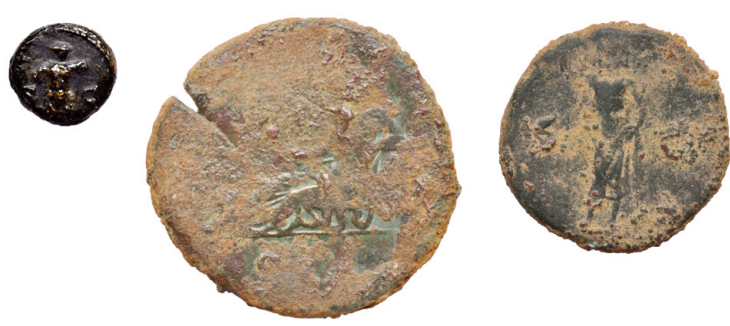

5
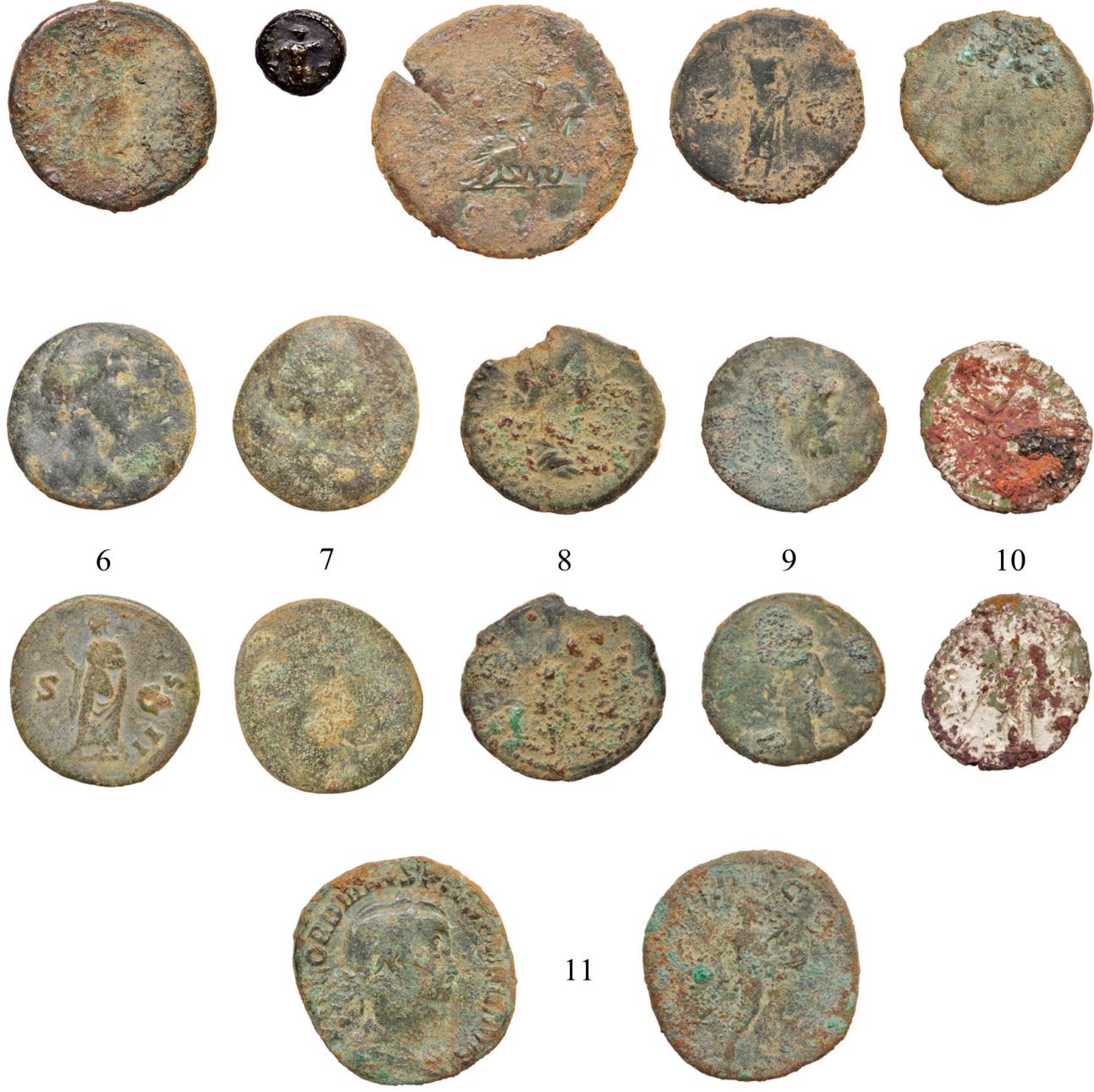

Lámina 1. Catálogo monedas n.os 1 a 11. 
Rev.: VIRTVS AVG. Virtus a izquierda, con escudo y cetro largo.

Ceca/fecha: Roma, 260-261 dC.

Medidas: 2,36 g; $12 \mathrm{~mm}$.

Ref.: ¿RIC V-1 317?; Cunetio 919 y ss.

MPV: 41902 .

Procedencia: U.E. 1111 , punto de hallazgo 009. Se encontró, junto con la moneda n. ${ }^{\circ} 7$ del catálogo, en una nivelación de arcilla roja clara en una de las habitaciones del ala este del Edificio A, pars rustica.

\section{Antoniniano de Galieno (253-268 dC)}

Anv.: [GALLIE]NVS AVG. Busto radiado y barbado de Galieno a derecha.

Rev.: MARTI PACIFERO. Marte de pie a la izquierda, sosteniendo rama de olivo en la mano derecha y lanza en la izquierda; detrás, escudo.

Ceca/fecha: Roma, 265-267 dC.

Medidas: $1,16 \mathrm{~g} ; 12 \mathrm{~mm}$.

Ref.: RIC V-1 236; Cunetio 1149.

MPV: 41913.

Procedencia: U.E. 1295, punto de hallazgo 027. Formaba parte, junto con las monedas n. ${ }^{\text {os }} 1$ y 22 del presente inventario, del conjunto recuperado en la segunda campaña de excavaciones, en un relleno de tierra arcillosa rojiza que contenía abundante material cerámico y amortizaba las estancias situadas al fondo del Edificio C, horreum.

\section{Antoniniano de Galieno (253-268 d.)}

Anv.: GALLIENVS AVG. Busto radiado y barbado de Galieno a derecha.

Rev.: [AET]ER - NITAS AVG. Sol de pie a izquierda con mano levantada y sosteniendo globo. Ceca/fecha: Roma, 253-268 dC.

Medidas: $1,95 \mathrm{~g} ; 12 \mathrm{~mm}$.

Ref.: ¿RIC V-1 160?; Cunetio 1169 y ss.

MPV: 41915.

Procedencia: U.E. 1306, punto de hallazgo 030. Apareció durante la segunda campaña de excavaciones en el umbral abierto a inicios del siglo in en la pared oeste del edificio del torculario.

\section{Antoniniano de Galieno (253-268 dC)}

Anv.: [GALLIENVS AVG]. Busto radiado y barbado de Galieno a derecha.

Rev.: ¿[SALVS] AVG. Salus de pie a la izquierda, alimentando serpiente en una patera?

Ceca/fecha: -

Medidas: 1,03 g; $12 \mathrm{~mm}$.

Ref.: -

MPV: 41920.

Procedencia: U.E. 1637, punto de hallazgo 49. Junto con las monedas n. ${ }^{o s} 10,27,32,36$ y del botón n. ${ }^{\circ} 51$ del presente catálogo, constituye parte del depósito localizado durante la tercera campaña de excavaciones en una de las habitaciones del ala este de la pars rustica. Las seis monedas fueron halladas en el interior de un pequeño hoyo excavado en su pavimento de mortero, que se encontraba relleno de tierra arcillosa rojiza muy suelta.

16. Antoniniano de Galieno (25 -268 dC)

Anv.: [GALLIENV]S AVG. Busto radiado de Galieno a derecha.

Rev.: Frustro. 
Ceca/fecha: -

Medidas: 1,80 g; $12 \mathrm{~mm}$.

Ref.: -

MPV: 41925.

Procedencia: U.E. 1638, punto de hallazgo 052. Hallada en la tercera campaña de excavaciones muy próxima a las monedas n. ${ }^{\mathrm{os}} 6$ y 33 entre los vertidos de limos y materia orgánica de una conducción que, procedente del patio de la pars rustica, desaguaba al exterior del Edificio A.

17. Antoniniano de Galieno (253-268 dC)

Anv.: [GALLIENVS AVG]. Busto radiado y barbado de Galieno a derecha.

Rev.: [FORTVNA REDVX]. Fortuna de pie a la izquierda, sosteniendo timón en globo con su mano derecha y cornucopia con su izquierda.

Ceca/fecha: Roma, 260-268 dC.

Medidas: 1,61 g; $11 \mathrm{~mm}$.

Ref.: ¿RIC V-1 193?; Cunetio 1217 y ss.

MPV: 41928.

Procedencia: U.E. 1641, punto de hallazgo 056. La moneda fue recuperada en la tercera fase de excavaciones en un nivel superficial de tierra arenosa rosada, homogénea, fina y compacta, localizado en el sector nororiental de la villa.

18. Antoniniano de Galieno (253-268 dC)

Anv.: [GALLIENVS AVG]. Busto radiado y barbado de Galieno a derecha.

Rev.: Frustro.

Ceca/fecha: -

Medidas: $2,37 \mathrm{~g} ; 13 \mathrm{~mm}$.

Ref.: -

MPV: 42335.

Procedencia: U.E. 1726, punto de hallazgo 079. Formaba parte, junto con las monedas n. ${ }^{\text {os }} 23$ y 34 del presente catálogo, de un conjunto de tres piezas escondidas en el extremo norte de una de las habitaciones del ala oeste del Edificio A, en la pars rustica de la villa. Se recuperaron en la tercera campaña de excavaciones del interior de un nivel de tierra arcillosa suelta, muy fina, de color marrón rojizo.

19. Antoniniano de Galieno (253-268 dC)

Anv.: [GALLIENVS AVG]. Busto radiado y barbado de Galieno a derecha.

Rev.: [SECVRIT P]ERPET. Securitas de pie apoyada en columna, con piernas cruzadas y sosteniendo cetro.

Ceca/fecha: Roma, 260-268 dC.

Medidas: $2,30 \mathrm{~g} ; 12 \mathrm{~mm}$.

Ref.: ¿RIC V-1 280?; Cunetio 1246 y ss.

MPV: 42345.

Procedencia: U.E. 1799, punto de hallazgo 106. Hallada durante la tercera campaña de excavaciones sobre una tegula completa, que se disponía horizontalmente en una pequeña fosa excavada en el pavimento de tierra de una de las estancias del ala norte del Edificio A, pars rustica. Se encontró en un nivel muy suelto de tierra arenosa de color pardo.

20. Antoniniano de Salonina (260-268 dC)

Anv.: COR SALONINA AVG. Busto de Salonina cubierto con media luna a derecha. 
Rev.: ¿AVG IN PACE. Salonina sedente a izquierda portando rama de olivo y cetro? Ceca/fecha: Mediolanum (Milán), 260-268 dC (bajo Galieno).

Medidas: 2,08 g; $14 \mathrm{~mm}$.

Ref.: ¿RIC V-1 57?

MPV: 42341.

Procedencia: U.E. 1745, punto de hallazgo 098. Recuperada con la moneda n. 35 del catálogo, en la esquina sureste de una de las estancias del ala norte del Edificio A, pars rustica. Ambas piezas permanecían ocultas en un nivel de tierra arcillosa roja y suelta con presencia esporádica de alguna grava de grano fino. En el mismo contexto se halló también la moneda n. ${ }^{\circ} 29$, localizada hacia la esquina opuesta de la habitación.

21. Antoniniano de Póstumo (259/260-269 dC)

Anv.: [IMP C POSTVMVS P F AVG]. Busto radiado y barbado Póstumo a derecha con coraza.

Rev.: Frustro.

Ceca/fecha: -

Medidas: 2,64 g; $16 \mathrm{~mm}$.

Ref.: -

MPV: 42346.

Procedencia: U.E. 1626, punto de hallazgo 107. Hallada en la habitación de la esquina noroeste del Edificio A, en la pars rustica de la villa. Procede de una capa horizontal de piedras de mediano tamaño dispuestas homogéneamente con escasa arcilla rojiza, probablemente introducida en ella por medio de una fosa que no fue identificada, excavada desde el nivel del pavimento de tierra superpuesto.

\section{Antoniniano de Claudio II (268-270 dC). Imitación hispánica}

Anv.: DIVO CLAVDIO. Busto radiado de Claudio II a derecha con coraza.

Rev.: CONSECRATIO. Águila.

Ceca/fecha: Post $270 \mathrm{dC}$.

Medidas: 1,65 g; $12 \mathrm{~mm}$.

Ref.: RIC V-1 266.

MPV: 41914.

Procedencia: U.E. 1295, punto de hallazgo 027. Se halló en la segunda campaña de excavaciones en el nivel de amortización de las estancias situadas al fondo del Edificio C, horreum. Junta a ella se recuperaron también las monedas $n .^{\text {os }} 1$ y 13 del presente catálogo.

\section{Antoniniano de Claudio II (268-270 dC). Imitación hispánica}

Anv.: DIVO CLAVDIO. Busto radiado de Claudio II a derecha con coraza.

Rev.: CONSECRATIO. Águila.

Ceca/fecha: Post $270 \mathrm{dC}$.

Medidas: $2,81 \mathrm{~g} ; 11 \mathrm{~mm}$.

Ref.: RIC V-1 266.

MPV: 42336.

Procedencia: U.E. 1726, punto de hallazgo 079. Se halló en la tercera campaña de excavaciones junto a las monedas n. ${ }^{\text {os }} 18$ y 34 del inventario. Permanecían ocultas dentro de un nivel de tierra marrón rojiza muy fina, en el extremo norte de una de las habitaciones del ala oeste del Edificio A, en la pars rustica de la villa.

24. Antoniniano de Claudio II (268-270 dC). Imitación hispánica Anv.: DIVO [CLAVDIO]. Busto radiado de Claudio II a derecha. 
Rev.: [CONSECRATIO]. Altar encendido de consagración. Dividido en cuatro secciones o plano. Ceca/fecha: Post $270 \mathrm{dC}$.

Medidas: 1,42 g; $11 \mathrm{~mm}$.

Ref.: RIC V-1 257.

MPV: 42338.

Procedencia: U.E. 1669, punto 082. Hallada durante las excavaciones de la tercera campaña en la esquina sureste de una de las habitaciones del ala oeste del Edificio A, en la pars rustica. Se encontró en el interior de un relleno de tierra roja de textura arenosa con nódulos de cal y algunas gravas.

25. Antoniniano de Claudio II (268-270 dC). Imitación hispánica

Anv.: DI[VO CLAV]DIO. Busto radiado de Claudio II a derecha.

Rev.: CO[NSE]CRATIO. Altar encendido de consagración. Dividido en cuatro secciones o plano. Ceca/fecha: Post $270 \mathrm{dC}$.

Medidas: 1,96 g; $12 \mathrm{~mm}$.

Ref.: RIC V-1 257.

MPV: 42343.

Procedencia: U.E. 1757, punto de hallazgo 093. Hallada en una de las estancias del ala norte del Edificio A, pars rustica, próxima a la moneda n. ${ }^{\circ} 28$ del catálogo. Ambas proceden de un nivel homogéneo de tierra arcillosa de color rosado, reseca, arenosa y fina, bajo el nivel de circulación de la habitación tras las reformas de finales del siglo III o inicios del IV.

\section{Antoniniano de Claudio II (268-270 dC) ¿Imitación hispánica?}

Anv.: [¿IMP CLAVDIVS P F AVG?]. Busto radiado de Claudio II a derecha con coraza.

Rev.: Frustro.

Ceca/fecha: -

Medidas: $1,74 \mathrm{~g} ; 12 \mathrm{~mm}$.

Ref.: - .

MPV: 41906.

Procedencia: U.E. 1214, punto de hallazgo 022. Se encontró en la tercera campaña de excavaciones en el ángulo noroeste del patio del Edificio A, en la pars rustica de la villa. Procede de un nivel superficial de tierra arcillosa color marrón amarillento que se hallaba alterado por las labores agrícolas. Contenía placas desplazadas de mortero de cal, gravas, escasas piedras de mediano tamaño y fragmentos de tegulae.

27. Antoniniano de "imitación bárbara» período de Tétrico I (post 271/273-274 dC)

Anv.: [¿C PIV ESV TETRICVS CAES?]. Busto de emperador con corona radiada a derecha de Tétrico II, hijo de Tétrico I.

Rev.: Frustro.

Ceca/fecha: Quizás Hispania o la Gallia a finales del siglo III dC.

Medidas: 3,13 g; $13 \mathrm{~mm}$.

Ref.: -

MPV: 41921.

Procedencia: U.E. 1637, punto de hallazgo 49. Pertenece al conjunto de seis monedas, junto con las n. ${ }^{\text {os }} 10,15,32,36$ y el botón n.$^{\circ} 51$ del catálogo, formando un depósito hallado en la tercera campaña de excavaciones en uno de los laterales de una estancia del ala este del Edificio A, pars rustica, en un pequeño hoyo excavado en su pavimento de mortero. 
28. Antoniniano de «imitación bárbara" período de Tétrico I (post 271/273-274 dC)

Anv.: [¿IMP TETRICVS P F AVG?]. Busto de emperador con corona radiada a derecha de Tétrico II, hijo de Tétrico I.

Rev.: [...]XA. Paz estante mirando hacia la izquierda sosteniendo rama de oliva y cetro. Ceca/fecha: Quizás Hispania o la Gallia a finales del siglo III dC.

Medidas: 1,67 g; $11 \mathrm{~mm}$.

Ref.: -

MPV: 42342.

Procedencia: U.E. 1757, punto de hallazgo 092. Se recuperó en un nivel de tierra arcillosa rosada muy fina, bajo el nivel de circulación de una de las estancias del ala norte del Edificio A, pars rustica, próxima a la moneda n. ${ }^{\circ} 25$ del catálogo.

29. Antoniniano frustro de "imitación bárbara"

Anv.: Busto de emperador con corona radiada a derecha (quizá Tétrico I o II).

Rev.: Frustro.

Ceca/fecha: ¿Siglo III dC?

Medidas: 2,56 g; $9 \mathrm{~mm}$.

Ref.: -

MPV: 42340.

Procedencia: U.E.: 1745, punto de hallazgo 087. Se halló en una de las estancias del ala norte del Edificio A, pars rustica, junto a la moneda catalogada con el n. ${ }^{\circ} 20$ y muy cerca de la n. ${ }^{\circ} 35$. Aparecieron en la tercera campaña de excavaciones en un nivel de tierra arcillosa suelta rojiza con algunas gravas finas.

\section{Antoniniano de Claudio II (268-270 dC)}

Anv.: [IMP CLAVDIVS P F AVG]. Busto radiado de Claudio II a derecha con coraza.

Rev.: ¿[FIDES MILIT]. Fides de pie, con cabeza a izquierda y manteniendo estandarte? Ceca/fecha: -

Medidas: 2,47 g; $11 \mathrm{~mm}$.

Ref.: -

MPV: 41905.

Procedencia: U.E. 1176, punto de hallazgo 021. Procede de una de las habitaciones del ala norte del Edificio A, en la pars urbana de la villa, oculta bajo el nivel de circulación de la estancia tras la fase de reformas de finales del siglo III o inicios del IV dC.

\section{Antoniniano de Quintilo $(270 \mathrm{dC})$}

Anv.: IMP C M AVR CL QVINTILLVS AVG. Busto radiado de Quintilo a derecha con coraza. Rev.: FORTVNA REDVX. Fortuna de pie a izquierda, sosteniendo timón y cornucopia. En el campo derecho $\mathrm{Z}$ como marca de ceca.

Ceca/fecha: Roma, $270 \mathrm{dC}$.

Medidas: $2,58 \mathrm{~g} ; 14 \mathrm{~mm}$.

Ref.: RIC V-1 20; Cunetio 2342.

MPV: 41907.

Procedencia: U.E. 1224, punto de hallazgo 024. Hallada con la moneda n. ${ }^{\circ} 8$ del presente inventario, a lo largo de la tercera campaña de excavaciones en el gran vertedero de cenizas en el patio de servicio del balneum durante su último momento de uso. 

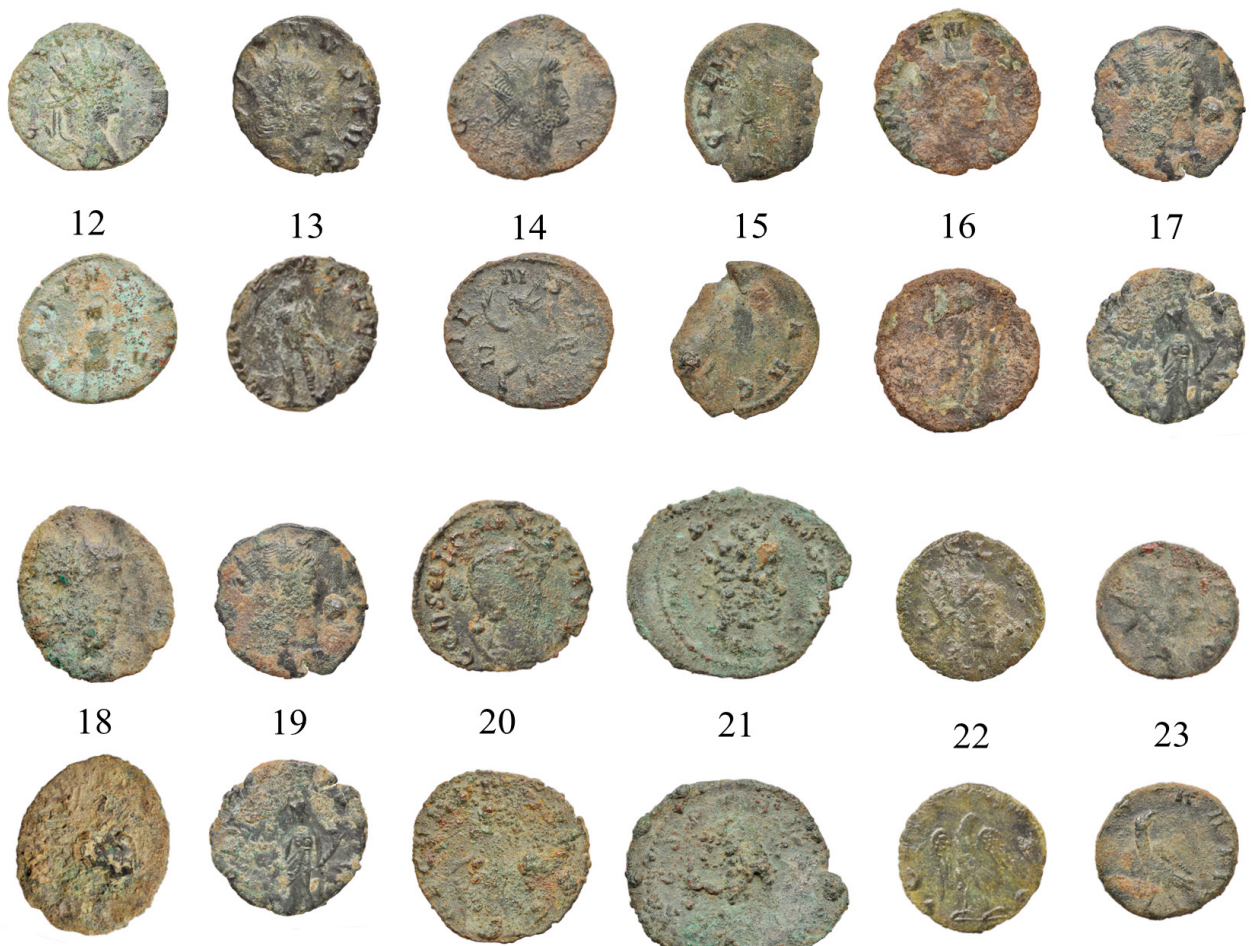

19

20

21

22

23
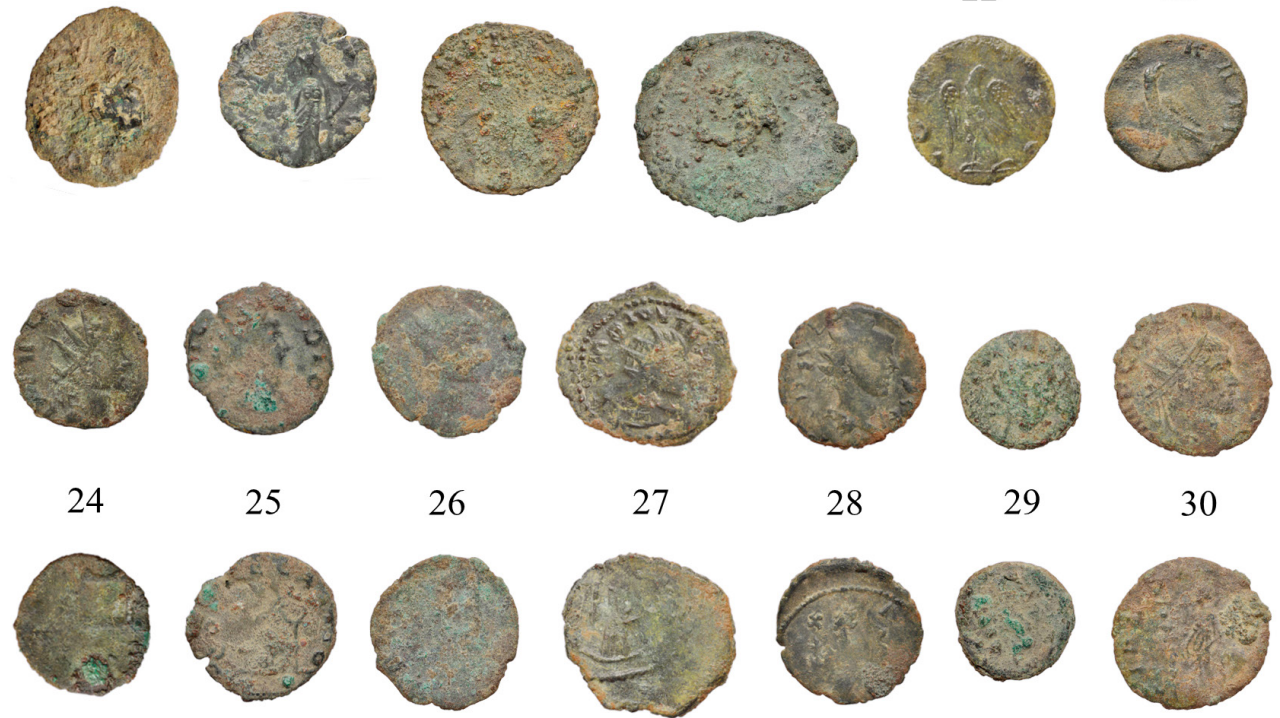

29

30

Lámina 2. Catálogo monedas n.os 12 a 30. 


\section{Antoniniano de Claudio II (268-270 dC)}

Anv.: IMP C CLAVDIVS AVG. Busto radiado de Claudio II a derecha con coraza.

Rev.: AEQVITAS AVG. Aequitas de pie a izquierda, sosteniendo balanza y cornucopia.

Ceca/fecha: Roma, 268-270 dC.

Medidas: $1,75 \mathrm{~g} ; 13 \mathrm{~mm}$.

Ref.: RIC V-1 14; Cunetio 1976 y ss.

MPV: 41919.

Procedencia: U.E. 1637, punto de hallazgo 49. Forma parte, con las monedas n. ${ }^{\text {os }} 10,15,27,36$ y del botón n. ${ }^{\circ} 51$, del conjunto de seis monedas halladas en un pequeño hoyo excavado en el pavimento de mortero de una de las estancias del ala este del Edificio A, pars rustica.

\section{Antoniniano de Claudio II (268-270 dC)}

Anv.: IMP C CLAVDIVS AVG. Busto radiado de Claudio II a derecha con coraza.

Rev.: FELICITAS AVG. Felicitas de pie, con la cabeza a la izquierda, con caduceo en la mano derecha y cornucopia en la izquierda.

Ceca/fecha: Roma, 268-270 dC.

Medidas: $3,13 \mathrm{~g} ; 15 \mathrm{~mm}$.

Ref.: RIC V-1 32; Cunetio 2034.

MPV: 41927.

Procedencia: U.E: 1638, punto de hallazgo 054. Recuperada durante la tercera campaña de excavaciones con la moneda . $^{\circ} 6$ del presente inventario en un nivel de limos negruzcos vertidos al exterior del Edificio A, pars rustica, por una conducción procedente de su patio. Muy próxima a ellas se halló también la moneda n. ${ }^{\circ} 16$.

\section{Antoniniano de Claudio II (268-270 dC)}

Anv.: IMP C CLAVDIVS AVG. Busto radiado de Claudio II a derecha con coraza.

Rev.: FIDES EXERCI. Fides con drapeado, parada hacia la derecha, sosteniendo insignia en cada mano.

Ceca/fecha: Roma, 268-270 dC.

Medidas: 3,62 g; $14 \mathrm{~mm}$.

Ref.: RIC V-1 36; Cunetio 2006 y ss.

MPV: 42337.

Procedencia: U.E. 1726, punto de hallazgo 079. La moneda se recuperó junto a las monedas n. ${ }^{\text {os }} 18$ y 23 del catálogo, formando parte de un mismo conjunto. Se hallaron durante la tercera campaña de excavaciones en un nivel de tierra arcillosa suelta y muy fina de color marrón rojizo.

\section{Antoniniano de Aureliano (270-275 dC)}

Anv.: [IMP AVRELIA]NVS AVG. Busto radiado de Aureliano a derecha con coraza.

Rev.: ¿FE[LIC SAECVLI / S]. Felicitas de pie hacia la izquierda sosteniendo un caduceo largo en la izquierda y un gancho en la derecha sobre altar?

Ceca/fecha: ¿Mediolanum (Milán), 270-275 dC?

Medidas: $4,36 \mathrm{~g} ; 16 \mathrm{~mm}$.

Ref.: ¿RIC V-1 122?

MPV: 42339.

Procedencia: U.E.: 1745, punto de hallazgo 083. Se halló en el centro de una de las estancias del ala norte del Edificio A, pars rustica, muy próxima a las monedas catalogadas con los n. ${ }^{\text {os }} 20$ y 29. Todas ellas aparecieron durante la tercera campaña de excavaciones en un nivel de tierra arcillosa suelta rojiza con algunas gravas finas. 


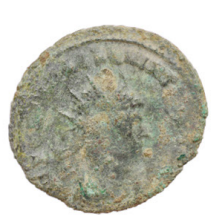

31
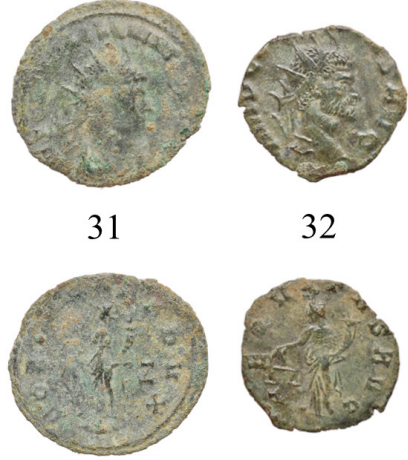

32
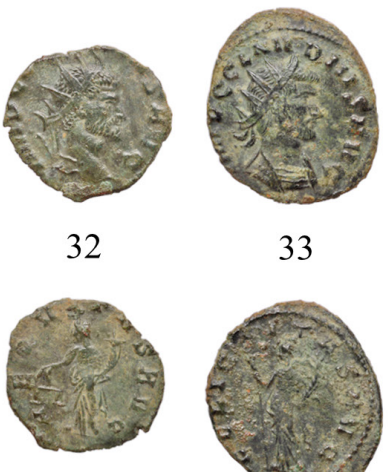

33
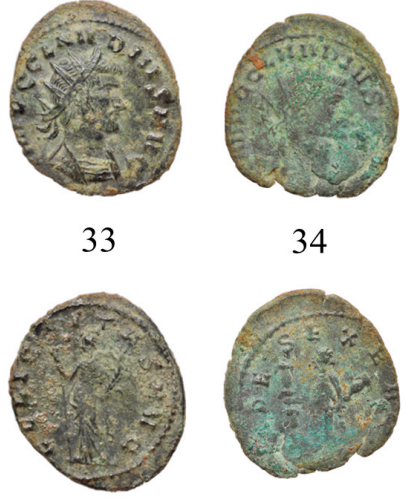

34
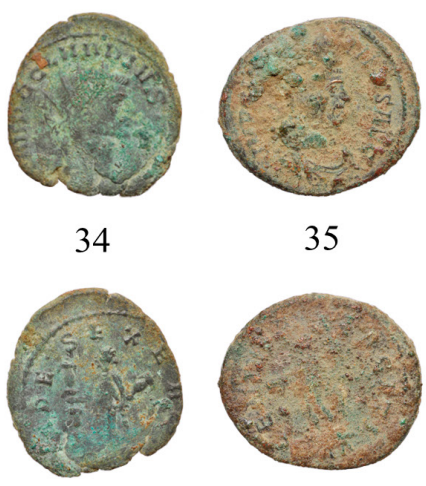

35
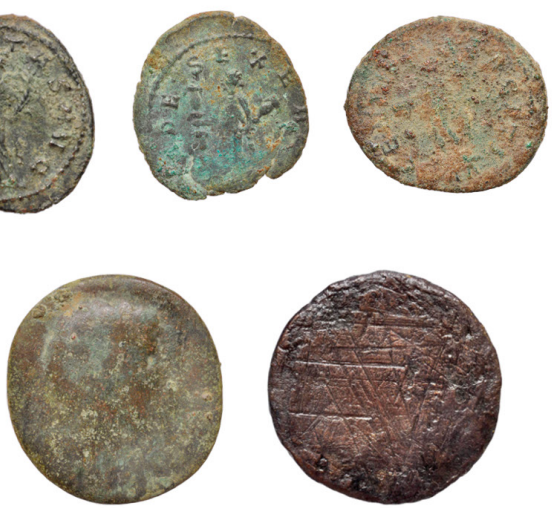

39
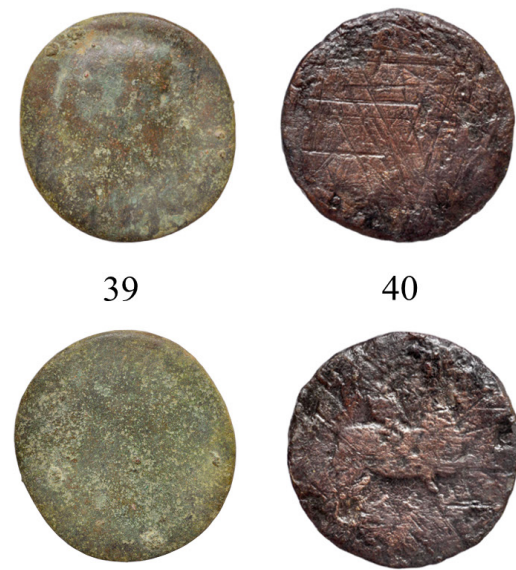

40
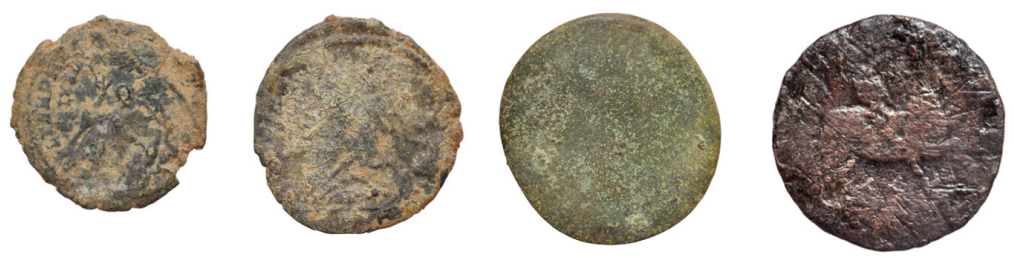

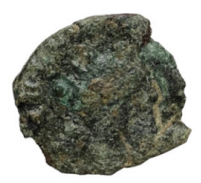

41

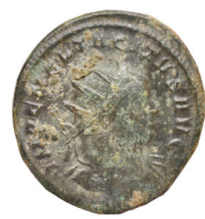

36
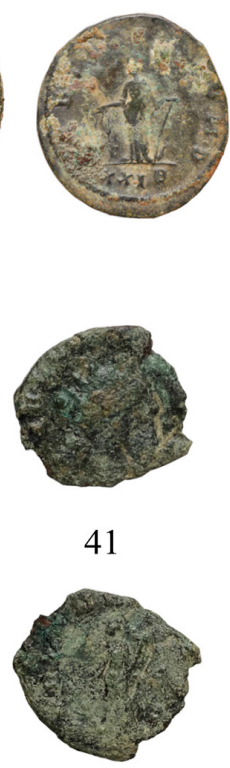
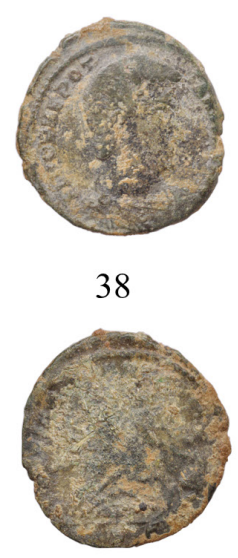

38

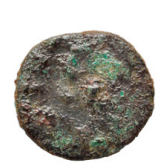

43 42

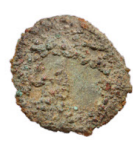

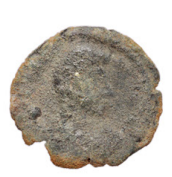

44

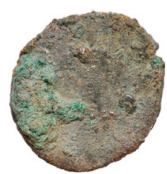

45

Lámina 3. Catálogo monedas n.os 31 a 46. 


\section{Antoniniano de Tácito (275-276 dC)}

Anv.: IMP C M CL TACITVS AVG. Busto radiado de Tácito a derecha con coraza.

Rev.: LAETITIA FVND / XXIB. Laetitia estante hacia la izquierda sosteniendo corona en su mano derecha y ancla en su izquierda.

Ceca/fecha: Roma, 275-276 dC.

Medidas: $3,39 \mathrm{~g} ; 16 \mathrm{~mm}$.

Ref.: RIC V-1 89.

MPV: 41922.

Procedencia: U.E. 1637, punto de hallazgo 49. Hallada durante la tercera campaña de excavaciones en el lateral de una de las estancias del ala este del Edificio A, pars rustica, en un pequeño hoyo excavado en su pavimento de mortero, donde se recuperaron asimismo las monedas n. ${ }^{\text {os }} 10,15,27,32$ y del botón $n .^{\circ} 51$ del presente catálogo.

\section{AE3 de Constancio II (355-361 dC)}

Anv.: D N CONSTAN-TIVS P F AVG / A. Busto diademado y drapeado de Constancio II a derecha con coraza.

Rev.: [FEL TEMP REPARATIO]. Soldado armado llevando un escudo en su brazo izquierdo y lanceando a un jinete tirado en el suelo sobre su caballo.

Ceca/fecha: Siglo IV dC.

Medidas: 4,35 g; $14 \mathrm{~mm}$.

Ref.: -

MPV: 41909.

Procedencia: U.E.: 1230, punto de hallazgo 025. Esta moneda y la siguiente del catálogo proceden de los niveles de derrumbe del tejado del atrio de la residencia principal de la villa, en su esquina sudoriental, caracterizados por la cantidad presente de material latericio y restos de enlucido de cal.

\section{AE2 de Nepociano (350 dC)}

Anv.: FL POP NEPOT-IANVS P F AVG. Busto barbado de Nepociano con coraza a derecha.

Rev.: [GLORIA ROMANORVM]. Emperador montado a caballo hacia la derecha, sin escudo, alanceando a bárbaro arrodillado delante del caballo con la mano levantada; debajo del caballo, escudo y lanza rota.

Ceca/fecha: Roma, 3-30 de junio de 350 dC.

Medidas: $5,26 \mathrm{~g} ; 16 \mathrm{~mm}$.

Ref.: RIC VIII 200.

MPV: 41910.

Procedencia: U.E.: 1230, punto de hallazgo 025. Esta moneda y la precedente se encontraron en los derrumbes de la esquina sudoriental del tejado del atrio de la residencia principal, entre grandes cantidades de material latericio y restos de enlucido de cal.

\section{As frustro}

Anv.: Busto de emperador a derecha. Muy posiblemente Adriano.

Rev.: Frustro.

Ceca/fecha: Roma, 117-138 dC.

Medidas: 7,47 g; $17 \mathrm{~mm}$.

Ref.: -

MPV: 42344. 
Procedencia: U.E. 1795, punto de hallazgo 104. Se encontró en las excavaciones de la tercera campaña en un paquete de tierra compacta reseca de color marrón rojizo, homogénea y fina, dentro de una de las habitaciones del ala oriental del Edifico A, pars rustica.

\section{As frustro}

Anv.: Busto de emperador a derecha. Muy posiblemente Adriano.

Rev.: ¿[COS III P P / S C]? Adriano en atuendo militar a caballo y sosteniendo la lanza en reposo con la mano derecha (?).

Ceca/fecha: ¿Roma, 132-134 dC?

Medidas: $6,42 \mathrm{~g} ; 18 \mathrm{~mm}$.

Ref.: ¿RIC II 717c?

MPV: 42629.

Procedencia: U.E. 1008, sin punto de hallazgo. Hallada en un nivel superficial alterado por trabajos agrícolas.

\section{Antoniniano frustro}

Anv.: Busto radiado a derecha.

Rev.: [¿AEQVITAS AVG o FORTVNA REDVX?]. Diosa drapeada hacia la derecha y sosteniendo cornucopia.

Ceca/fecha: Siglo III dC.

Medidas: 2,65 g; $13 \mathrm{~mm}$.

MPV: 42632.

Procedencia: U.E. 1008, sin punto de hallazgo. Hallada en el nivel superficial que cubría el total de la villa.

\section{Antoniniano frustro}

Anv.: Busto de emperador con corona radiada a derecha (quizá Tétrico I o II...)

Rev.: Frustro.

Ceca/fecha: Siglo III dC.

Medidas: 1,36 g; $9 \mathrm{~mm}$.

Ref.: -

MPV: 42347.

Procedencia: U.E. 1042, sin punto de hallazgo. Se recuperó durante los trabajos de excavación, desarrollados en la segunda campaña, del interior de una zanja para la instalación de una tubería de suministro de agua que seccionaba longitudinalmente el sector norte de la villa. Su relleno, de tierra arenosa suelta de color rojizo, contenía abundantes fragmentos de argamasa procedentes de la destrucción de las estructuras constructivas.

\section{Antoniniano frustro}

Anv.: ¿Busto con corona radiada a derecha?

Rev.: Frustro.

Ceca/fecha: Siglo III dC.

Medidas: 1,82 g; $11 \mathrm{~mm}$.

Ref.: -

MPV: 41899.

Procedencia: U.E. 1049, punto de hallazgo 004. Hallada junto a la moneda n. ${ }^{\circ} 11$ en un gran relleno de tierra arcillosa de color rojizo, con abundantes placas de pavimento y fragmentos de tegulae, que nivelaba las habitaciones del ala norte del edificio de la pars rustica. 
44. AE3 frustro de Constancio II o Juliano II (?)

Anv.: [...]. Busto de emperador a derecha con coraza.

Rev.: [SPES REIPVBLICAE]. Emperador de pie a la izquierda, vestido militarmente, sosteniendo globo con su mano derecha y lanza inversa con su izquierda.

Ceca/fecha: ca. 355-363 d.C.

Medidas: $1,90 \mathrm{~g} ; 12 \mathrm{~mm}$.

Ref.: -

MPV: 41918.

Procedencia: U.E.: 1661, punto de hallazgo 047. La pieza, recuperada en la tercera campaña de excavaciones, apareció en un nivel de tierra roja suelta de textura arcillosa con manchas negruzcas de cenizas en la misma estancia del ala oeste del Edificio A que el depósito formado por las monedas $n .{ }^{\text {os }} 18,23$ y 34 del presente catálogo.

\section{AE3/antoniniano frustro}

Medidas: $3,31 \mathrm{~g} ; 13 \mathrm{~mm}$.

Ref.: -

MPV: 41929.

Procedencia: U.E. 1674, punto de hallazgo 061. Se recuperó en la tercera campaña de excavaciones, apoyada directamente sobre el pavimento de tierra de una de las estancias que ocupaba el ángulo noroeste del Edificio A, pars rustica. Apareció junto a otros contados objetos que correspondían al último momento de uso de la habitación, anterior a las trasformaciones de época tardorromana.

\section{AE3/antoniniano frustro}

Medidas: $2,35 \mathrm{~g} ; 14 \mathrm{~mm}$.

MPV: 42631.

Procedencia: U.E. 1214, sin punto de hallazgo. Hallada en un nivel superficial de tierra alterada por trabajos agrícolas, con abundantes placas de mortero de cal, gravas, algunas piedras y fragmentos de tegulae.

\section{Cospel descompuesto (sestercio)}

Medidas: $25,17 \mathrm{~g} ; 23 \mathrm{~mm}$.

MPV: 41901.

Procedencia: U.E.: 1602, punto de hallazgo 046. Esta moneda y la n. ${ }^{\circ} 48$ proceden de un estrato de tierra arcillosa de textura arenosa, fina, de color rojizo intenso, con presencia de algunas gravas y piedras pequeñas, que se localizó en las excavaciones desarrolladas en el patio de servicio del balneum durante la tercera campaña de intervención.

\section{Cospel descompuesto (sestercio)}

Medidas: 28,63 g; $25 \mathrm{~mm}$.

MPV: 41917.

Procedencia: U.E.: 1602, punto de hallazgo 046. Procede, igual que la moneda n. ${ }^{\circ} 47$, de un nivel de arcilla arenosa, fina, color rojizo intenso, con algunas gravas y piedras pequeñas, localizado en el patio de servicio del balneum durante la tercera campaña de intervención.

49. Cospel descompuesto (as)

Medidas: 11,90 g; $21 \mathrm{~mm}$.

MPV: 41904. 
Procedencia: U.E.: 1155, punto de hallazgo 019. Hallada en el interior de la fábrica de un muro de mampostería irregular trabada con tierra que reocupó la franja norte del patio del Edificio A en época tardorromana.

50. Peseta de la II República Española (1937)

Anv.: Alegoría de Hispania representada por una joven con larga melena; en su alrededor REPVBLICA ESPAÑOLA.

Rev.: Tallo de vid con una hoja de parra y racimo de uvas, junto al valor de la moneda (1 peseta) y debajo, la fecha (1937).

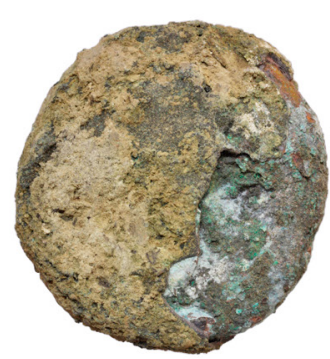

47

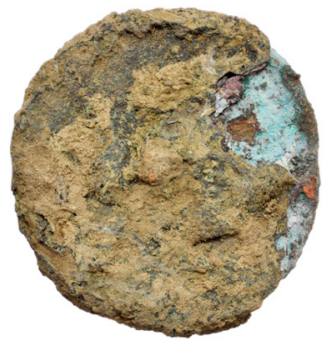

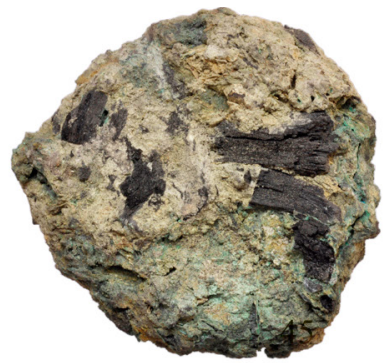

48

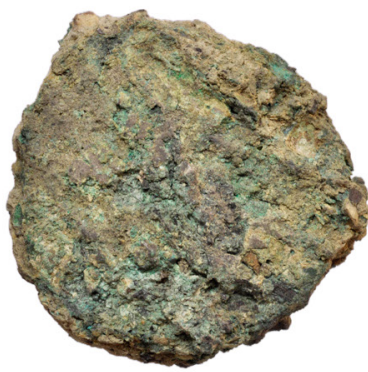

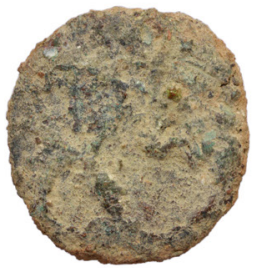

49

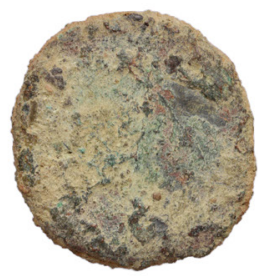

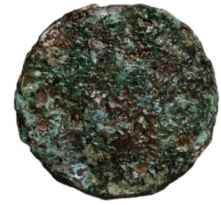

50

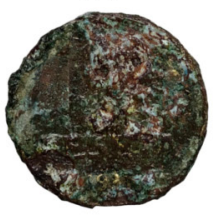

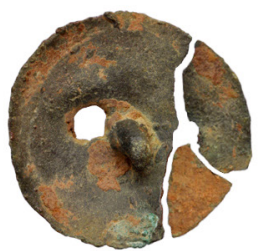

$51(\times 2)$

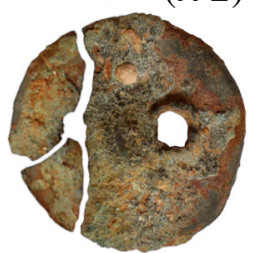

Lámina 4. Catálogo monedas n. os 47 a 50 y botón n. ${ }^{0} 51$. 
Medidas: 4,69 g; $19 \mathrm{~mm}$.

MPV: 42630.

Procedencia: U.E. 1042, sin punto de hallazgo. Procede del relleno de una zanja contemporánea para la instalación de suministro de agua que seccionaba longitudinalmente el sector norte de la villa.

\section{Botón de bronce}

Medidas: 1,96 g; $19 \mathrm{~mm}$.

MPV: 41924.

Procedencia: U.E. 1637, punto de hallazgo 49. Hallada con las monedas n. ${ }^{\text {os }} 10,15,27,32$ y 36 del catálogo, en un pequeño hoyo excavado en el pavimento de mortero de una de las estancias del ala este del Edificio A, pars rustica. Se recuperó durante la tercera campaña de excavaciones.

\section{Bibliografía}

ARASA GIL, F. y ROSSELLÓ VERGER, V. M., 1995, Les vies romanes del territori valencià, Conselleria d'Obres Públiques, Urbanisme i Transports, València.

BANAJI, J., 2001, Agrarian Change in Late Antiquity. Gold, Labour, and Aristocratic Dominance, Oxford University Press, Oxford.

BASTIEN, P., 1985, Imitations of Roman Bronze Coins, A.D. 318-363, American Numismatic Society Museum Notes 30, 143-177.

BESLY, E. y BLAND, R., 1983, The Cunetio Treasure: Roman Coinage of the Third Century A.D., Bristish Museum, Londres.

BOST, J. P., CHAVES TRISTÁN, F., DEPEYROT, G., HIERNARD, J. y RICHARD RALITE, J. C., 1987, Belo IV. Les monnaies, Casa de Velázquez, Madrid.

BOST, J. P., 1992-1993, Villa y circulación monetaria: hipótesis de trabajo, Studia Histórica. Historia Antigua 10-1 1, 219-225.

BOWES, K., 2013, Villas, Taxes and Trade in Fourth Century Hispania, en L. LAVAN (ed.) Local Economies? Production and Exchange of Inland Regions, Late Antiquity Archaeology 10/1, Leiden, 191-226.
BURNETT, A. M., 1987, Coinage in the Roman World, Seaby, Londres.

BURNETT, A. M., 1991, Interpreting the Past. Coins, British Museum, Londres.

CALLU, J. P., 1969, La politique monétaire des empereurs romains de 238 à 311 , Bibliothèque des Écoles françaises d'Athènes et de Rome, París.

CALLU, J. P., 1974, Remarques sur le trésor de Thamusida III: les DIVO CLAVDIO en Afrique du Nord, Mélanges de l'École Française de Rome. Antiquité 86/1, 532-554.

CANO GARCÍA, G. M., 1974, Sobre una posible "centuriatio" en el regadío de la acequia de Montcada (Valencia), en Estudios sobre centuriaciones romanas en España, Universidad Autónoma de Madrid, Madrid, 115-127.

CARMONA GONZÁLEZ, P. y RUIZ PÉREZ, J. M., 2007, El medio físico: el territorio como escenario de los regadíos históricos, en J. HERMOSILLA PILA (ed.), El patrimonio hidráulico del Bajo Turia: l'Horta de València, Generalitat Valenciana, València, 30-44.

CEPEDA OCAMPO, J. J., 1991, La circulación de moneda de Magnencio en Hispania, en 
VII Congreso Nacional de Numismática (Madrid, 1989), Sociedad Iberoamericana de Estudios Numismáticos, Madrid, 371-379.

CEPEDA OCAMPO, J. J., 1996, Del Antoninianus al Nummus Centenionalis. Tesoros y depósitos monetarios en la Hispania tardorromana (260-423 d.C.), Universidad del País Vasco, Vitoria-Gasteiz (tesis doctoral inédita).

CRAWFORD, M. H., 1986, Numismática, en M. H. CRAWFORD (ed.), Fuentes para el estudio de la Historia Antigua, Taurus, Madrid, 197-248.

GONZÁLEZ GARCÍA, A., 201 la, La inflación en el Imperio Romano de Diocleciano a Teodosio, Documenta et Instrumenta 9, 123-152.

GONZÁLEZ GARCÍA, A., 201 lb, Moneda y guerra en el reinado de Constancio II (337-61), ArqueoUCA 1, 115-128.

GONZÁLEZ VILLAESCUSA, R., 1996, Paisaje agrario, regadío y parcelarios en la huerta de Valencia: nuevos planteamientos desde el análisis morfológico, en II Coloquio de Historia y Medio Ambiente (Almería, 1995). Agricultura y regadio en alAndalus, Almería, 343-360.

GONZÁLEZ VILLAESCUSA, R., 2002, Las formas de los paisajes mediterráneos (ensayos sobre las formas, funciones y epistemología parcelarias: estudios comparativos en medios mediterráneos entre la antigüedad y época moderna), Universidad de Jaén, Jaén.

GONZÁLEZ VILLAESCUSA, R., 2007, La huerta cuando no lo era. La configuración histórica del territorio de Valentia, en J. HERMOSILLA (coord.), El patrimonio hidráulico del Bajo Turia: L'Horta de València, Generalitat Valenciana, València, 45-59.

GRIERSON, P., 1956, The Roman Law of Counterfeiting, en R. A. G. CARSON y C. H. V. SUTHERLAND (eds.), Essays in Roman Coinage presented to Harold Mattingly, Oxford University Press, Oxford, 240- 261.

GOZALBES FERNÁNDEZ DE PALENCIA, M., 1999, Los hallazgos monetarios del Grau Vell (Sagunt, València), Generalitat Valenciana, València.

HARL, K. W., 1996, Coinage in the Roman Economy, 300 B.C. to A.D. 700, JHU Press, Baltimore.
HORTELANO UCEDA, I., 2007, El Pou de la Sargueta (Riba-roja de Túria, Valencia). Una villa en el territorio de Valentia, Lucentum 26, 115-126. DOI: http://dx.doi.org/10.14198/ LVCENTVM2007.26.05

HORTELANO UCEDA, I., 2008, La red de acueductos de la Valentia romana: canales de abastecimiento rural al sur del Túria, Lucentum 27, 69-85. DOI: http://dx.doi.org/10.14198/ LVCENTVM2008.27.05

HORTELANO UCEDA, I., 2011-2012, Torcularia inéditos de dos villas del territorio de Valentia (conventus Carthaginiensis), en J. M. NOGUERA CELDRÁN y J. A. ANTOLINOS MARÍN (coords.), De vino et oleo Hispaniae. Áreas de producción y procesos tecnológicos del vino y el aceite en la Hispania romana, Coloquio Internacional, Anales de Prehistoria y Arqueología 27-28, 273-281.

HOWGEGO, C., 1995, Ancient History from Coins, Routledge, Londres-Nueva York.

LEWIT, T., 2004, Villas, Farms and the Late Roman Rural Economy (third to fifth centuries $A D$ ), BAR Intemational Series 568, Oxford.

LLEDÓ CARDONA, N., 2007, La moneda en la Tarraconense mediterránea en época romana imperial, Servicio de Investigación Prehistórica, València.

LÓPEZ SÁNCHEZ, F., 2000, Tiranía y legitimación del poder en la numismática de Magnencio y Constancio II (350-353 d.C.), Faventia 22/1, 59-86.

MAROT SALSAS, T., 1994, El significado cronológico de las imitaciones bajo-imperiales: estudio de un tesorillo hallado en Barcelona, en VIII Congreso Nacional Numismática (Avilés, 1992), Sociedad Iberoamericana de Estudios Numismáticos, Madrid, 381-399.

MAROT SALSAS, T., 2001, Aproximación a la circulación monetaria en la península ibérica y las islas baleares durante los siglos v y vi. La incidencia de las emisiones vándalas y bizantinas, Revue Numismatique 152, 157-190.

MARTÍNEZ CHICO, D., 2014, Notas sobre un peculiar numisma imitativo de Constancio II hallado cerca de la Vía de la Plata, Acta Numismàtica 44, 159-165. 
MARTínEZ CHICO, D., 2016, Un cuadrante inédito de las emisiones anónimas (81-161 d.C.) encontrado en Cástulo, ¿conexión con centros mineros propiedad del Senado?, Rivista Italiana di Numismatica e Scienze Affini 117, 271-274.

MARTÍNEZ CHICO, D. y GONZÁLEZ FERNÁNDEZ, R., 2018, Hallazgos monetarios en la villa romana de Los Villaricos (Mula, Murcia), Archivo de Prehistoria Levantina 32, 285-299.

MORENO Y CASANOVA, J. J., 2007, Un nuevo ejemplo de reacuñación bajoimperial. Gaceta Numismática 166/167, 21-29.

MORENO RESANO, E., 2009, La usurpación de Nepociano (350 d.C.): Una revisión historiográfica, Veleia 26, 297-322.

PALOMERO PLAZA, S., 1987, Las vías romanas en la provincia de Cuenca, Diputación Provincial, Cuenca

PINGARRÓN SECO, E., 1981, Rastreo de una "centuriatio" en la zona sur de la Huerta de Valencia, Cuadernos de Geografía 29, 161-176.

RIC II = MATTINGLY, H. y SYDENHAM, E.A. 1926, The Roman Imperial Coinage, vol. II, Spink and Son Ltd., Londres.

RIC III = MATTINGLY, H. y SYDENHAM, E.A., 1930, The Roman Imperial Coinage, vol. III, Spink and Son Ltd., Londres.

RIC IV-1 = MATTINGLY, H. y SYDENHAM, E. A., 1936, The Roman Imperial Coinage, vols. IV-I, Spink and Son Ltd., Londres.
RIC IV-2 = MATTINGLY, H., SYDENHAM, E. A. Y SUTHERLAND, C. H. V., 1938, The Roman Imperial Coinage, vols. IV-II, Spink and Son Ltd., Londres.

RIC IV-3 = MATTINGLY, H., SYDENHAM, E. A. y SUTHERLAND, C. H. V., 1949, The Roman Imperial Coinage, vols. IV-III, Spink and Son Ltd., Londres.

RIC V-1 = WEBB, P. H. 1972, The Roman Imperial Coinage, vols. V-I, Spink and Son Ltd., Londres.

RIC VI = SUTHERLAND, C. H. V., 1967, The Roman Imperial Coinage, vol. VI, Spink and Son Ltd., Londres.

RIC VIII = KENT, J. P. C., 1981, The Roman Imperial Coinage, vol. VIII, Spink and Son Ltd., Londres.

RIPOLLÈS ALEGRE, P. P., 2002, La moneda romana imperial y su circulación en Hispania, Archivo Español de Arqueología 75/185-186, 195-214.

SYDENHAM, E. A., 1919, The Roman Monetary System. Part II, Reprinted from Numismatic Chronicle, Fourth Series, vol. XIX, Royal Numismatic Society, Londres, 114-171.

VAN HEESCH, J., 1979, Studie over de semis en de quadrans van Domitianus tot en met Antoninus Pius, Gante, Rijksuniver diteit te Gant (tesis doctoral inédita). Consulta: 7 de octubre de 2018. Disponible en <http://www.academia. $\mathrm{edu} / 20381200>$. 